Biochemistry. Author manuscript; available in PMC 2016 August 31.

Published in final edited form as:

Biochemistry. 2007 April 17; 46(15): 4565-4579. doi:10.1021/bi602526k.

\title{
Gauging a Hydrocarbon Ruler by an Intrinsic Exciton Probe ${ }^{\dagger}$
}

\author{
M. Adil Khan $\ddagger, \S$, Chris Neale $\|$, Catherine Michaux ${ }^{\perp}$, Régis Pomés $\|, @$, Gilbert G. Privé $\|, \perp$, \\ Robert W. Woody\#, and Russell E. Bishop ${ }^{*},, \S, \|$ \\ Departments of Laboratory Medicine and Pathobiology and of Biochemistry, University of Toronto, \\ Toronto, ON, Canada M5S 1A8, Department of Medical Biophysics, University of Toronto, and \\ Division of Molecular and Structural Biology, Ontario Cancer Institute, Toronto, ON, Canada M5G \\ 2M9, Department of Structural Biology and Biochemistry, Hospital for Sick Children, Toronto, ON, \\ Canada M5G 1X8, Department of Biochemistry and Molecular Biology, Colorado State University, \\ Fort Collins, Colorado 80523, and Department of Biochemistry and Biomedical Sciences, \\ McMaster University, Hamilton, ON, Canada L8N $3 Z 5$
}

\section{Abstract}

The structural basis of lipid acyl-chain selection by membrane-intrinsic enzymes is poorly understood because most integral membrane enzymes of lipid metabolism have proven refractory to structure determination; however, robust enzymes from the outer membranes of Gram-negative bacteria are now providing a first glimpse at the underlying mechanisms. The methylene unit resolution of the phospholipid: lipid A palmitoyltransferase PagP is determined by the hydrocarbon ruler, a 16-carbon saturated acyl-chain-binding pocket buried within the transmembrane $\beta$-barrel structure. Substitution of Gly88 lining the floor of the hydrocarbon ruler with Ala or Met makes the enzyme select specifically 15- or 12-carbon saturated acyl chains, respectively, indicating that hydrocarbon ruler depth determines acyl-chain selection. However, the Gly88Cys PagP resolution does not diminish linearly because it selects both 14- and 15-carbon saturated acyl chains. We discovered that an exciton, emanating from a buried Tyr26-Trp66 phenol-indole interaction, is extinguished by a local structural perturbation arising from the proximal Gly88Cys PagP sulfhydryl group. Site-specific S-methylation of the single Cys afforded Gly88Cys- $S$-methyl PagP, which reasserted both the exciton and methylene unit resolution by specifically selecting 13-carbon saturated acyl chains for transfer to lipid A. Unlike the other Gly88 substitutions, the Cys sulfhydryl group recedes from the hydrocarbon ruler floor and locally perturbs the subjacent Tyr26 and Trp66 aromatic rings. The resulting hydrocarbon ruler expansion

\footnotetext{
†This work was supported by CIHR Operating Grants MOP-43886 awarded to R.E.B. and MOP-57922 awarded to G.G.P. R.P. is a CRCP chairholder.

"To whom correspondence should be addressed: Department of Biochemistry and Biomedical Sciences, McMaster University, Hamilton, ON, Canada L8N 3Z5. Telephone: (905) 525-9140, ext. 28810. Fax: (905) 522-9033. bishopr@ mcmaster.ca.

${ }_{*}$ Department of Laboratory Medicine and Pathobiology, University of Toronto.

\$cMaster University.

UDepartment of Biochemistry, University of Toronto.

$\perp_{\text {Department }}$ of Medical Biophysics, University of Toronto, and Ontario Cancer Institute.

${ }^{@}$ Hospital for Sick Children.

\#Colorado State University.

SUPPORTING INFORMATION AVAILABLE

Oligonucleotide primers used for site-directed mutagenesis and cloning (Table S1), far-UV CD spectra of PagP at different temperatures (Figure S1), analysis of PagP Trp66 mutants folded in vivo (Figure S2), and theoretical CD spectra of PagP, its in silico aromatic amino acid substitutions, and their difference spectra (Figure S3). This material is available free of charge via the Internet at http://pubs.acs.org.
} 
thus occurs at the exciton's expense and accommodates an extra methylene unit in the selected acyl chain. The hydrocarbon ruler-exciton juxtaposition endows PagP with a molecular gauge for probing the structural basis of lipid acyl-chain selection in a membrane-intrinsic environment.

The diversity of acyl chains found in membrane lipids reflects the ability of cells to modulate membrane biophysical states and to employ specific lipids in signal transduction pathways $(1,2)$. Enzymes of lipid metabolism encounter an effective combinatorial library in their substrates and are necessarily endowed with mechanisms for selecting specific acylchain types. Most lipid-metabolizing enzymes of known structure represent soluble globular domains that exist either free in solution or as monotopic membrane proteins $(3,4)$. Some of these structures indicate how enzymes interact with soluble lipid substrates and have revealed acyl-chain-measuring devices known as hydrocarbon rulers $(5,6)$. The monotopic membrane enzyme structures further indicate how globular domains interact with their substrates at the periphery of lipid bilayers. However, many key lipid metabolic steps are catalyzed by integral membrane enzymes, which are embedded in their substrates and encounter a low-dielectric milieu not normally accessible to soluble globular protein domains. The biophysical basis of integral membrane lipid-protein recognition is advancing with increasing numbers of determined structures, but integral membrane enzymes of lipid metabolism have mostly proven refractory to structure determination (7). Exceptions are found in the outer membranes of Gram-negative bacteria, which have recently revealed integral membrane protein structures for a phospholipase, a lipid deacylase, and a lipid acyltransferase (8-11). These integral membrane $\beta$-barrel enzymes are more robust than most $\alpha$-helical integral membrane enzymes of lipid metabolism, and are now providing insights into the molecular mechanisms of lipid acyl-chain selection within a lipid bilayer environment.

Many integral membrane $\beta$-barrel proteins can be purified in an unfolded state and refolded at high concentrations in detergent micelles, which are transparent to certain spectroscopic analyses of protein structure and stability. Extrinsic spectroscopic probes can be introduced into proteins to study structure-function relationships, but these studies must be carefully scrutinized to avoid artifacts arising from structural perturbations introduced by the probe itself. If Trp and Tyr residues are localized in a functionally interesting protein region, their aromatic side chains can be exploited as intrinsic probes to prevent such artifacts. However, it can be difficult or impossible to deconvolute the signals that arise from a single aromatic side chain if multiple copies are present in a given protein. More rarely, two or more Trp and/or Tyr residues that interact within specific geometrical and distance constraints can afford a so-called exciton interaction. The exciton effect arises from the delocalization of the excited states of two interacting chromophores (12). The strong $\pi \rightarrow \pi^{*}$ transitions arising from Trp and Tyr side chains do not on their own generate Cotton effects that can be detected by circular dichroism (CD) ${ }^{1}$ spectroscopy. Cotton effects arise when parallel components of electric and magnetic dipole transition moments are combined, and strict group theoretical rules show that this cannot happen when a chromophore possesses centers

${ }^{1}$ Abbreviations: CD, circular dichroism; DSC, differential scanning calorimetry; ESI-MS, electrospray ionization mass spectrometry; LDAO, lauroyldimethylamine $N$-oxide; LPS, lipopolysaccharide; MNBS, methyl $p$-nitrobenzenesulfonate. 
or planes of symmetry (13). When they are placed in a chiral environment, such as that provided by the polypeptide backbone of a protein molecule, an exciton effect arising from a pair of interacting chromophores can generate two Cotton effects of equal magnitude and opposite sign that are slightly separated by the so-called Davydov energy (14). The resultant of these two overlapping Cotton effects is a bisignate curve known as an exciton couplet, which can be detected in the far-UV region of a protein CD spectrum (15).

Exciton theory lies at the heart of protein CD spectroscopy because it accounts for key spectroscopic signatures that arise between $\pi \rightarrow \pi^{*}$ transitions in interacting peptide groups located within the secondary structural elements. However, exciton couplets arising from interacting aromatic side chains have largely been ignored in protein secondary structure analysis, despite their clear overlap in the far-UV range with the signals that arise from secondary structure (16). Due to the strong rotational strengths associated with the a-helix, the weaker aromatic exciton couplets in the far-UV range are most apparent in proteins with low a-helical content, but their presence can significantly influence the far-UV CD spectrum of any protein $(17,18)$. Theoretical analyses show that exciton couplets arising from aromatic side-chain interactions are among the more reliably predicted CD spectroscopic signatures that can occur within a protein molecule (19). Algorithms that consider aromatic exciton interactions for predicting a protein $\mathrm{CD}$ spectrum from a given set of crystal structure coordinates are available. One can usually pinpoint interacting aromatic side chains associated with an exciton couplet by systematically replacing each aromatic amino acid with Ala in silico and subtracting the calculated CD spectrum from that for the wild-type protein (19). Given the strict geometrical requirements of the exciton effect, aromatic exciton couplets are anticipated to be extraordinarily sensitive to local structural perturbations that might well be introduced during the experimental modification of any given protein structure. A considerable degree of untapped potential lies in the identification and application of aromatic exciton interactions to study protein function in the current era of structural proteomics. In this paper, we report evidence of the modulation of an aromatic exciton couplet in a lipid-metabolizing integral membrane enzyme.

We have been investigating the structure and function of PagP, a 161-amino acid membrane protein that resides within the outer membranes of pathogenic Gram-negative bacteria such as Escherichia coli (20). PagP is an enzyme of lipid metabolism that transfers a palmitate chain from a phospholipid molecule to the lipid A (endotoxin) component of lipopolysaccharide (LPS) (21). The Gram-negative outer membrane is an asymmetric bilayer that normally displays LPS in the outer leaflet and restricts phospholipids to the inner leaflet (22). This asymmetric lipid organization creates a permeability barrier to hydrophobic antibiotics and detergents that are normally encountered in the host and natural environments (23). PagP provides bacteria with a degree of resistance to host-derived antimicrobial agents and attenuates the ability of endotoxin to activate the TLR-4 host defense pathway $(24,25)$. Additionally, PagP can function as an apical sensory transducer that reports perturbations of lipid asymmetry by a novel signal transduction mechanism in bacteria (S. Kim, W. Jia, E. Vinogradov, C. Gyles, and R. Bishop, unpublished observations). 
$\mathrm{PagP}$ is an eight-stranded antiparallel $\beta$-barrel with a short $\alpha$-helix at its $\mathrm{N}$-terminus, and it sits in the membrane with the barrel axis tilted by roughly $25^{\circ}$ (Figure 1A) (11). The PagP palmitate recognition pocket, known as the hydrocarbon ruler, resides within the interior of the $\beta$-barrel and is localized in the outer LPS-exposed region of the protein (11). A single molecule of the detergent lauroyldimethylamine $N$-oxide (LDAO) serves to identify the position of the hydrocarbon ruler within the $\beta$-barrel interior (Figure 1A). Two discontinuities in $\beta$-strand hydrogen bonding within this LPS-exposed region provide obvious routes for lateral access of lipids to the hydrocarbon ruler $(10,26)$. The implication that PagP depends on the aberrant migration of phospholipids into the outer leaflet is supported by observations that the enzyme normally remains dormant in outer membranes until its activity is directly triggered by perturbations to lipid asymmetry (27).

A striking enzymological feature of PagP lies in its ability to distinguish a 16-carbon saturated palmitate chain in phospholipids from all other acyl chains, even those that differ by only a single methylene unit $(11,21)$. The depth of the PagP hydrocarbon ruler, which is lined at its base by Gly88, determines this single-methylene unit resolution (Figure 1B). PagP lacks any Cys residues, but it is particularly rich in aromatic amino acids and includes 10 Phe, 11 Tyr, and 12 Trp residues, not including the N-terminal signal peptide. During our efforts to modulate acyl-chain selection by site-specific chemical methylation of a Gly88Cys PagP mutant, we have discovered an exciton couplet that could be pinpointed to an interaction between Tyr26 and Trp66 at the floor of the hydrocarbon ruler. We demonstrate that this intrinsic exciton probe can provide a gauge for reporting methylene unit resolution in the PagP hydrocarbon ruler.

\section{EXPERIMENTAL PROCEDURES}

\section{Expression and Purification of PagP}

To purify PagP in a denatured state, we expressed it without its native signal peptide in $E$. coli BL21(DE3) transformed with the plasmid pETCrcAH $\Delta \mathrm{S}$ or its mutant derivatives that were constructed using the QuickChange protocol (Stratagene) as described previously (10). All oligonucleotide primers used in our mutagenesis and cloning procedures are identified in Table S1 of the Supporting Information. Bacteria were cultured in $1 \mathrm{~L}$ of Luria-Bertani medium supplemented with ampicillin at $100 \mu \mathrm{g} / \mathrm{mL}$ and grown to an optical density at 600 $\mathrm{nm}$ of 0.50 and then induced with $1 \mathrm{mM}$ isopropyl $\beta$-D-thiogalactopyranoside for $3 \mathrm{~h}$. The induced cells were harvested, suspended in $20 \mathrm{~mL}$ of $50 \mathrm{mM}$ Tris- $\mathrm{HCl}(\mathrm{pH} 8.0)$ and $5.0 \mathrm{mM}$ EDTA, and broken by being passed twice through a French pressure cell at $10000 \mathrm{psi}$, and the insoluble material was recovered by centrifugation in a Beckman MLA-80 rotor at 27 $000 \mathrm{rpm}$ and $4{ }^{\circ} \mathrm{C}$ for $20 \mathrm{~min}$ using an Optima MAX-E ultracentrifuge. The pellets were washed in $20 \mathrm{~mL}$ of $50 \mathrm{mM}$ Tris- $\mathrm{HCl}(\mathrm{pH} 8.0)$ and $2 \%$ Triton X-100 followed by $20 \mathrm{~mL}$ of $50 \mathrm{mM}$ Tris- $\mathrm{HCl}(\mathrm{pH} \mathrm{8.0)}$ and then solubilized in $10 \mathrm{~mL}$ of $50 \mathrm{mM}$ Tris- $\mathrm{HCl}(\mathrm{pH}$ 8.0) and 6 $\mathrm{M} \mathrm{Gdn-HCl}$. Supernatants were collected after centrifugation and loaded onto a $5 \mathrm{~mL}$ bed of His-bind resin (Novagen) that was charged with $50 \mathrm{mM} \mathrm{NiSO}_{4}$ and equilibrated with 3 column volumes of $10 \mathrm{mM}$ Tris- $\mathrm{HCl}$ (pH 8.0), $250 \mathrm{mM} \mathrm{NaCl}, 6 \mathrm{M} \mathrm{Gdn}-\mathrm{HCl}$, and $5 \mathrm{mM}$ imidazole. The sample was applied to the column and washed with 10 column volumes of the equilibration buffer, followed by 5 column volumes of $10 \mathrm{mM}$ Tris- $\mathrm{HCl}$ (pH 8.0), 250 
$\mathrm{mM} \mathrm{NaCl}, 6 \mathrm{M} \mathrm{Gdn}-\mathrm{HCl}$, and $20 \mathrm{mM}$ imidazole. The samples were eluted in a step gradient using $5 \mathrm{~mL}$ each of $35,50,75,100$, and $125 \mathrm{mM}$ imidazole. SDS-PAGE confirmed the presence of purified PagP in the 100 and $125 \mathrm{mM}$ imidazole fractions, which were pooled and dialyzed against distilled water, and the precipitated protein was collected. The protein was resuspended in $8.8 \mathrm{~mL}$ of $8 \mathrm{M} \mathrm{Gdn}-\mathrm{HCl}$ and $0.34 \mathrm{M}$ Tris- $\mathrm{HCl}(\mathrm{pH} 8.6)$, and the concentration of the purified wild-type protein was determined, using a calculated extinction coefficient ( $\varepsilon_{280}$ ) of $82630 \mathrm{M}^{-1} \mathrm{~cm}^{-1}$, to be $6.67 \mathrm{mg} / \mathrm{mL}$ for a total yield of $58.7 \mathrm{mg}$ (28). The remaining mutant proteins were obtained in similar yields.

PagP Trp66 mutant proteins that failed to refold in vitro could be folded in vivo when they were expressed with the intact signal peptide in plasmid pETCrcAH and then purified directly from LDAO-solubilized membranes in $1 \mathrm{mg}$ quantities from $1 \mathrm{~L}$ cultures as described previously (21).

\section{Methylation of PagP}

Wild-type and Gly88Cys mutant PagP in Gdn- $\mathrm{HCl}$ were subjected to an S-methylation procedure using methyl $p$-nitrobenzenesulfonate (MNBS) (29). Control reaction mixtures excluding only MNBS were also prepared, and the four reactions were carried out in capped glass tubes. Protein in $8 \mathrm{M} \mathrm{Gdn}-\mathrm{HCl}$ and $0.34 \mathrm{M}$ Tris- $\mathrm{HCl}(\mathrm{pH}$ 8.6) was adjusted to 5 $\mathrm{mg} / \mathrm{mL}$ in a final volume of $5 \mathrm{~mL}$ containing $6 \mathrm{M} \mathrm{Gdn}-\mathrm{HCl}, 0.25 \mathrm{M}$ Tris- $\mathrm{HCl}(\mathrm{pH} 8.6), 3.3$ $\mathrm{mM}$ EDTA, and $25 \%(\mathrm{v} / \mathrm{v})$ acetonitrile. The solutions were flushed with $\mathrm{N}_{2}$ for $1 \mathrm{~min}$ to create an anoxic barrier, and $50 \mu \mathrm{L}$ of $260 \mathrm{mM} \beta$-mercaptoethanol was added (10-50-fold molar excess of the protein). The tubes were tightly sealed, placed in a $50{ }^{\circ} \mathrm{C}$ bath for $1 \mathrm{~h}$, and then gradually cooled to $37^{\circ} \mathrm{C}$. Under the $\mathrm{N}_{2}$ barrier, $0.5 \mathrm{~mL}$ of $5.2 \mathrm{mM}$ MNBS (2-fold molar excess of the $\beta$-mercaptoethanol) was added, and the tubes were tightly sealed and placed in a $37{ }^{\circ} \mathrm{C}$ bath for $2 \mathrm{~h}$. The reactions were quenched via addition of $5 \mu \mathrm{L}$ of $14 \mathrm{M} \beta$ mercaptoethanol. The reaction mix was dialyzed exhaustively against distilled water, and the precipitated proteins were collected and dissolved in $10 \mathrm{~mL}$ of $10 \mathrm{mM}$ Tris- $\mathrm{HCl}(\mathrm{pH} \mathrm{8.0)}$ and $6 \mathrm{M} \mathrm{Gdn}-\mathrm{HCl}$. The protein yield was nearly quantitative $(25 \mathrm{mg}$ ) for all four samples. An aliquot of each sample $(0.5 \mathrm{~mL})$ was dialyzed against water and the precipitated protein used for mass spectrometry.

\section{Electrospray lonizatation Mass Spectrometry (ESI-MS)}

MS was performed at the Advanced Proteomics Facility at the Hospital for Sick Children. Our procedure for dissolving precipitated $\mathrm{PagP}$ was adapted from a prior study of lactose permease (30). Precipitated samples to be analyzed were dissolved in $5 \mathrm{~mL}$ of a $1: 1(\mathrm{v} / \mathrm{v})$ acetonitrile/1\% formic acid mixture at a concentration of $\sim 1 \mathrm{ng} / \mu \mathrm{L}$ just prior to ESI-MS and were injected directly into a triple-quadrupole mass spectrometer. The positive ion mode was used and the cone potential maintained at $48 \mathrm{eV}$ and the collision energy at $4 \mathrm{eV}$. The spectra were reconstructed using Mass Lynx 3.5. In one instance, a Sciex API III ${ }^{+}$triple-quadrupole mass spectrometer was used, but all other analyses were performed with a Micromass Quattro Ultima LC-ESI/APCI triple-quadrupole mass spectrometer. 


\section{Refolding of PagP}

Samples in $10 \mathrm{mM}$ Tris- $\mathrm{HCl}$ (pH 8.0), $6 \mathrm{M} \mathrm{Gdn}-\mathrm{HCl}$, and $20 \mathrm{mM} \beta$-mercaptoethanol were diluted dropwise ( 1 drop per $2 \mathrm{~s}$ ) into a 10-fold excess of $10 \mathrm{mM}$ Tris- $\mathrm{HCl}(\mathrm{pH} 8.0)$ and 20 $\mathrm{mM} \beta$-mercaptoethanol containing $0.5 \% \mathrm{LDAO}$ at room temperature with vigorous stirring and left to stir overnight at $4{ }^{\circ} \mathrm{C}$. The $\beta$-mercaptoethanol was excluded in subsequent refolding experiments using PagP mutants that lack any Cys residues. The refolding sample was then applied to a $4 \mathrm{~mL}$ bed of His-bind resin (Novagen) charged with $50 \mathrm{mM} \mathrm{NiSO}_{4}$ and equilibrated with $10 \mathrm{mM}$ Tris- $\mathrm{HCl}(\mathrm{pH} 8.0), 0.1 \%$ LDAO, and $5 \mathrm{mM}$ imidazole. The column was washed with 10 column volumes of the equilibration buffer and 10 column volumes of $10 \mathrm{mM}$ Tris- $\mathrm{HCl}(\mathrm{pH} 8.0), 0.1 \% \mathrm{LDAO}$, and $20 \mathrm{mM}$ imidazole and then eluted with $2 \mathrm{~mL}$ of $10 \mathrm{mM}$ Tris- $\mathrm{HCl}$ ( $\mathrm{pH} 8.0$ ), $0.1 \%$ LDAO, and $250 \mathrm{mM}$ imidazole. The sample was dialyzed against $10 \mathrm{mM}$ Tris- $\mathrm{HCl}(\mathrm{pH} 8.0)$ and $0.1 \%$ LDAO, and the refolded samples $(6 \mu \mathrm{g})$ were resolved via SDS-PAGE on $1 \mathrm{~mm}$ Novex $16 \%$ Tris glycine precast gels under reducing or nonreducing conditions (Invitrogen). The heated samples were boiled at $100{ }^{\circ} \mathrm{C}$ for $10 \mathrm{~min}$ before loading, and protein was stained using Coomassie blue dye. Disulfide bonds were encouraged to form under nonreducing conditions by uncapping the heated and unheated samples on the bench for several hours prior to loading on the gel. Refolded PagP protein concentrations were determined using either the bicinchoninic acid assay (31) or by absorbance using an extinction coefficient $\left(\varepsilon_{280}\right)$ determined experimentally by the Edelhoch method $(32,33)$.

\section{Spectroscopy}

Samples to be analyzed for $\mathrm{CD}$ were maintained at a concentration of $0.3-0.1 \mathrm{mg} / \mathrm{mL}$ in 10 $\mathrm{mM}$ Tris- $\mathrm{HCl}(\mathrm{pH} 8.0)$ and $0.1 \% \mathrm{LDAO}$ and were analyzed using a cuvette with a path length of $1 \mathrm{~mm}$. The samples were analyzed with either a Jasco J-812 or an Aviv $215 \mathrm{CD}$ spectrometer, each of which was linked to Peltier devices for temperature control. For each sample, three accumulations were averaged at a data pitch of $1 \mathrm{~nm}$ and a scanning speed of $10 \mathrm{~nm} / \mathrm{min}$. The temperature was maintained at $25^{\circ} \mathrm{C}$, and data sets were obtained from 200 to $280 \mathrm{~nm}$. For thermal denaturation profiles, samples at a concentration of $0.8-0.3 \mathrm{mg} / \mathrm{mL}$ in $10 \mathrm{mM}$ Tris- $\mathrm{HCl}(\mathrm{pH} 8.0)$ and $0.1 \% \mathrm{LDAO}$ were analyzed in a cuvette with a path length of $1 \mathrm{~mm}$. The samples were heated from 20 to $100{ }^{\circ} \mathrm{C}$ at a rate of $2{ }^{\circ} \mathrm{C} / \mathrm{min}$, with a response time of $16 \mathrm{~s}$.

\section{Differential Scanning Calorimetry (DSC)}

The specific heat capacity $\left(C_{p}\right)$ as a function of temperature was obtained in an N-DSC (cell volume of $0.3 \mathrm{~mL}$ ) at a scan rate of $1.0^{\circ} \mathrm{C} / \mathrm{min}$ and a pressure of $\sim 37 \mathrm{psi}$. The protein sample was first dialyzed overnight at $4{ }^{\circ} \mathrm{C}$ against $100 \mathrm{mM}$ sodium phosphate buffer $(\mathrm{pH}$ 8.0) with $0.05 \%$ LDAO. The solution was then degassed for $5 \mathrm{~min}$ before it was loaded into the DSC cells. A blank scan with buffer in both calorimeter cells was subtracted to correct for the difference between the cells. The DSC instrument that was employed was a CSC model 6100 Nano II. The software used to collect the data was DSCRUN, N-DSC control program (version 2.5.0.29s), Calorimetry Science Corp. The software used to visualize the data was cpcalc (version 2.1, Applied Thermodynamics), while the software used to process the data was Microcal TM (version 5.0, Microcal Software Inc.). 


\section{Theoretical Calculations of CD}

The CD spectrum for wild-type PagP was calculated using the X-ray structure (11) (PDB entry $1 \mathrm{THQ})$. The methods and parameters have been described previously $(18,34)$.

Calculations were also performed for mutants generated in silico by deletion, one by one, of each of the Tyr and Trp side chains in the vicinity of Gly88 in the crystal structure: Tyr26, Trp60, Trp66, Tyr70, Tyr87, and Trp156. (Phe side chains were not mutated because they have only the weak $260 \mathrm{~nm}$ band above $220 \mathrm{~nm}$.) In each case, a difference spectrum was calculated by subtracting the predicted spectrum of the mutant from that of the wild type, thus providing the contribution of the mutated side chain to the wild-type CD spectrum.

\section{Hydrocarbon Ruler Assays}

$\mathrm{Kdo}_{2}$-lipid A was prepared from heptose-deficient E. coli WBB06 as described previously (35) and quantified as described (36). Synthetic diacylphosphatidylcholines were obtained from Avanti Polar Lipids (Alabaster, AL). The hydrocarbon ruler assays were performed at $30{ }^{\circ} \mathrm{C}$ by a TLC-based radiolabeling procedure as described previously (11), except that 25 $\mu \mathrm{Ci}$ of $\left[{ }^{32} \mathrm{P}\right]$-orthophosphate was employed in place of sodium $\left[{ }^{14} \mathrm{C}\right]$-acetate.

\section{Molecular Dynamics}

We have used high-temperature simulated annealing to probe the local conformational changes induced by mutation of Gly88. The same procedure has been applied to two starting conformations. The initial conformation was the X-ray structure (11) (PDB entry 1THQ) in the absence of LDAO and crystal waters. Another starting conformation was obtained by equilibration of the X-ray structure containing a rebuilt L1 loop and bound LDAO, and embedded in an explicit 1,2-dimyristoyl-sn-glycero-3-phosphocholine (37) bilayer and TIP3P water (38). All nonprotein atoms were then removed. Residues His22 and His102 were protonated on $\mathrm{N}^{\delta 1}$, while residues His 33 and His67 were protonated on $\mathrm{N}^{\varepsilon 2}$. All simulations were carried out using the CHARMM software package(39) using the CHARMM22 all-hydrogen topology and parameter files (40). Parameters for the methylated cysteine residue were developed on the basis of methionine via removal of $\mathrm{C}^{\beta}$. All nonbonded interactions (Lennard-Jones and Coulombic) were switched off from 10 to $11 \AA$. The neglect of long-range electrostatic interactions is justified because conformational sampling is restricted to local side-chain rearrangements of neutral residues within a static protein framework.

Initial conformations of the mutants were obtained as follows. Hydrogen atoms to be replaced by heavy atoms were chosen such that the nascent side chain was in the LDAO binding pocket and pointed toward the extracellular region. Mutants were created according to the following succession: Gly88Ala $\left(\mathrm{H}^{\alpha 1} \rightarrow \mathrm{C}^{\beta}, \mathrm{H}^{\alpha 2} \rightarrow \mathrm{H}^{\mathrm{a}}\right)$, Ala88Cys $\left(\mathrm{H}^{\beta 3} \rightarrow \mathrm{S}^{\gamma}\right)$, Cys88-S-methyl $\left(\mathrm{H}^{\gamma} \rightarrow \mathrm{C}^{\delta}\right)$, and Cys- $S$-methyl88Met $\left(\mathrm{S}^{\gamma} \rightarrow \mathrm{C}^{\gamma}, \mathrm{C}^{\delta} \rightarrow \mathrm{S}^{\delta}, \mathrm{H}^{\delta 1} \rightarrow \mathrm{C}^{\mathcal{\varepsilon}}\right)$. A harmonic restraining potential was applied for $\mathrm{C}^{\prime}, \mathrm{N}^{\prime}, \mathrm{C}^{\mathrm{a}}$, and $\mathrm{O}^{\prime}$ atoms of residue 88 with a force constant of $10 \mathrm{kcal} \mathrm{mol}^{-1} \AA^{-2}$, and all other residues were held fixed. Each mutant was energy minimized.

In the remaining calculations, a harmonic restraining potential was applied to the backbone heavy atoms of residues Trp66, Gly68, Tyr70, X88, Thr108, and Leu128 with a force 
constant of $10 \mathrm{kcal} \mathrm{mol}^{-1} \AA^{-2}$ (greater by 1 order of magnitude for calculations starting from the X-ray structure). All other residues were held fixed. Each of the conformations resulting from the procedure outlined above was simulated at $3000 \mathrm{~K}$ for $75 \mathrm{ps}$. The temperature was controlled by Langevin dynamics with a friction coefficient of $2.0 \mathrm{ps}^{-1}$. High-temperature seed conformations were taken after 15, 25, 35, 45, 55, 65, and 75 ps. Each seed was then cooled to $206 \mathrm{~K}$ over a minimum of $1.3 \mathrm{~ns}$ by reducing the temperature to 0.8 of its previous value after each segment. Dynamics at and below $3000 \mathrm{~K}$ were produced with time steps of 0.5 and $1.0 \mathrm{fs}$, respectively. The final cooling step was followed by energy minimization.

Figures were generated with VMD version 1.8.3 (41) and rendered with POV-Ray version 3.6 (Persistence of Vision Pty. Ltd.). Trp66 and X88 are overlaid for all seven replicas. Contouring of the $\beta$-barrel interior was performed by HOLE with a cutoff radius of $1.4 \AA$ (42). For the wild type and each mutant, contours were generated on the basis of the initial wild-type structure plus the coordinates of residue 88 overlaid from all seven replicas. All other figures derived from the PagP crystal structure coordinates were rendered using PyMOL (43).

\section{RESULTS}

In our prior investigation, we analyzed membrane-derived wild-type PagP and its sitespecific mutants Gly88Ala, Gly88Cys, and Gly88Met (11). To improve the quality of these initial studies, we removed the signal peptide from each of the mutant proteins for expression and purification in a denatured state to be followed by refolding. Since PagP lacks any Cys residues, the single Cys in Gly88Cys PagP was available for a chemical methylation procedure that occurs in $\mathrm{Gdn}-\mathrm{HCl}$ needed to unfold PagP, which is necessary to expose the Cys residue and to normalize the reactivity of other functional groups (29) (Figure 1B,C). By synthesizing Gly88Cys- $S$-methyl PagP, we predicted that we could create a suite of hydrocarbon ruler mutants that select 15-carbon (Gly88Ala), 14-carbon (Gly88Cys), 13-carbon (Gly88Cys-S-methyl), and 12-carbon (Gly88Met) saturated acyl chains. The hydrocarbon ruler hypothesis predicts that the substituted amino acid side chain at position 88 will plug the floor of the hydrocarbon ruler and make it shallower by the same length as the introduced side chain. This change in hydrocarbon ruler dimensions should afford a corresponding shortening of the acyl chain that is selected in enzymatic assays.

\section{Site-Specific Chemical Modification of Gly88Cys PagP}

We subjected the unfolded wild-type and Gly88Cys PagP proteins to methylation with MNBS (Figure 1C) as described previously (29). Control reactions were also performed without MNBS. To detect the incorporation of a single methylene group (14.03 Da) into an $\sim 20 \mathrm{kDa}$ protein, we chose to determine the mass by ESI-MS. This method is incompatible with the $\mathrm{Gdn}-\mathrm{HCl}$ or LDAO used to keep PagP in solution, but we were able to develop a mild procedure, adapted from a much harsher one using formic acid to perform ESI-MS on lactose permease (30); our adaptation involves removing denaturants by dialysis against water and dissolving the precipitated protein in a 1:1 acetonitrile/1\% formic acid solution immediately prior to ESI-MS analysis. We could demonstrate that MNBS leads to a $14 \mathrm{Da}$ 
increase in the mass of the Gly88Cys mutant, but not in the wild-type protein, which lacks any Cys residues (Table 1). The mass spectra reveal that the Gly88Cys mutant in the absence of MNBS treatment forms two species, the major one being a disulfide-linked dimer (Figure 2). MNBS treatment of the Gly88Cys mutant reveals a single molecular species corresponding to a monomeric $\mathrm{S}$-methylated protein. These findings validate the claim that the methylation procedure is both quantitative and highly selective for Cys under the specified conditions (29). We were also able to verify the masses of the remaining PagP mutants by ESI-MS (Table 1).

\section{Evaluation of PagP Refolding}

The unfolded PagP variants were refolded by dilution into LDAO and evaluated by a qualitative SDS-PAGE assay (Figure 3). Many outer membrane proteins like PagP exhibit the phenomenon of heat modifiability on SDS-PAGE. In these gels, the unheated form of PagP appears folded and more compact as it migrates slightly ahead of its expected molecular mass of $20 \mathrm{kDa}$ (21). However, after irreversible heat denaturation, PagP migrates at its expected molecular mass. This explanation for the observed heat modifiability is reinforced by the observation that only the heat-denatured Gly88Cys PagP is capable of migrating as a disulfide-linked dimer in the nonreducing gel (Figure 3A). The single Cys in this mutant appears to be unexposed in the unheated sample, consistent with the fastermigrating species reflecting a folded state of the protein. Wild-type PagP and its Gly88 mutant derivatives all appeared to be adequately folded by this SDS-PAGE criterion.

\section{Spectroscopic Examination of Refolded PagP Mutants}

We wanted to determine whether subtler structural details could be ascertained by a more refined CD spectroscopic examination of the refolded PagP proteins. The LDAO micelles are transparent down to $200 \mathrm{~nm}$ in CD analysis of the refolded PagP proteins. The far-UV CD spectrum of wild-type PagP (Figure 4A,B) displays a negative CD band at $218 \mathrm{~nm}$ that is characteristic of the $\mathrm{n} \rightarrow \pi^{*}$ transition derived from peptide bonds in a largely $\beta$-sheet conformation (44). This observation is consistent with the $\beta$-barrel structure of PagP. However, the positive ellipticity at $232 \mathrm{~nm}$ is likely the first Cotton effect of an exciton couplet, which becomes fully apparent only by its absence in Gly88Cys PagP (Figure 4A). The second Cotton effect of this exciton couplet is largely superimposed on the $\beta$-sheet $\mathrm{n} \rightarrow$ $\pi^{*}$ transition. The Gly88Cys PagP sulfhydryl group appears to be responsible for extinguishing the exciton couplet, because Gly88Cys- $S$-methyl PagP restores the exciton couplet to its full strength. The far-UV CD spectra of Gly88Ala and Gly88Met PagP similarly exhibit a robust exciton couplet (Figure 4B).

We reasoned that the absence of the exciton couplet in Gly88Cys PagP might result from a local structural perturbation arising from the sulfhydryl group. We followed loss of the negative ellipticity maximum at $218 \mathrm{~nm}$ in thermal unfolding experiments using wild-type $\mathrm{PagP}$ and its hydrocarbon ruler mutants (Figure 4C,D). PagP was unfolded irreversibly in these experiments because it precipitated after incubation at $100^{\circ} \mathrm{C}$. However, the proteins that exhibit the exciton couplet all share a thermal denaturation temperature near $88^{\circ} \mathrm{C}$, while Gly88Cys PagP denatures near $65^{\circ} \mathrm{C}$ (Figure $4 \mathrm{C}$ ). The smaller perturbation apparent near $50{ }^{\circ} \mathrm{C}$ in all but Gly88Cys PagP likely represents loss of the excitonic Cotton effect that 
contributes to the ellipticity at $218 \mathrm{~nm}$ because a transition of a similar magnitude is also observed near $50{ }^{\circ} \mathrm{C}$ by following the loss of the associated positive ellipticity at $232 \mathrm{~nm}$ (Figure 5A). This finding suggests that the exciton is much more sensitive to heat, disappearing at a temperature that is easily tolerated by the $\beta$-barrel structure. The transition at $88^{\circ} \mathrm{C}$ most likely represents protein unfolding because wild-type $\mathrm{PagP}$ was shown to exhibit a thermal transition at the same temperature in a DSC experiment (Figure 5B).

Far-UV CD spectra recorded at high temperatures validate the disappearance of the excitonic signature prior to protein unfolding and reveal that residual $\beta$-structure remains at $92^{\circ} \mathrm{C}$ (Figure 5C). Precipitation ensuing at higher temperatures is consistent with the formation of intermolecular $\beta$-structure that would compensate for intramolecular $\beta$-structure lost during $\beta$-barrel unfolding, because both structures exhibit negative ellipticity at $218 \mathrm{~nm}$. Consequently, the different plateaus reached at high temperatures by the various mutants (Figure 4C,D) likely reflect different tendencies to form intermolecular $\beta$-structure in the denatured state. Compared to wild-type PagP, more extensive residual ellipticity is apparent at $92{ }^{\circ} \mathrm{C}$ in Gly88Cys-S-methyl PagP (Figure S1A of the Supporting Information), which is consistent with its lower plateau as observed in Figure 4C. In contrast to the aggregation observed in LDAO at high temperatures, a distinct conformation is indicated after heat denaturation in the presence of $1 \%$ SDS because we previously observed that heat-denatured PagP migrates in a monodisperse state via SDS-PAGE (Figure 3). We find that PagP retains the apparent excitonic signature associated with its $\beta$-barrel structure after dilution into $1 \%$ SDS at room temperature, but boiling the sample over the course of $1 \mathrm{~h}$ followed by cooling to room temperature reveals characteristics of an a-helical protein in far-UV CD spectra (Figure 5D). Helix formation in SDS is also indicated as a function of increasing temperature (Figure S1B of the Supporting Information) by a gradual increase in rotational strength, an associated red shift of the amide $\mathrm{n} \rightarrow \pi^{*}$ transition from 218 to $222 \mathrm{~nm}$, and the acquisition of a new negative ellipticity maximum at $208 \mathrm{~nm}$, which arises from exciton splitting of the amide $\pi \rightarrow \pi^{*}$ transition.

\section{Theoretical Exciton Analysis}

To pinpoint any aromatic amino acid residues that contribute to the observed exciton couplet, we used the high-resolution PagP crystal structure coordinates (11) (PDB entry $1 T H Q$ ) to predict the CD spectrum (Figure S3A of the Supporting Information). We were encouraged to find that calculations using standard methods and parameters $(18,34)$ reproduced the experimental positive $\mathrm{CD}$ band at $232 \mathrm{~nm}$ (predicted $[\theta]_{\max }=1500$ at 237 $\mathrm{nm})$. Analysis of the band responsible for this positive feature shows that it is located at 232 $\mathrm{nm}$ and is largely due to the $230 \mathrm{~nm}$ band of Tyr26 (69\%) and the $225 \mathrm{~nm}$ band of Trp66 (21\%), with contributions of 1-3\% from Trp60, Tyr70, Tyr87, and Trp156. This analysis was supported by calculations on in silico mutants in which Tyr26, Trp66, and other participants in the long-wavelength positive band were deleted. Deletion of Tyr26 gave negative CD throughout the 220-240 $\mathrm{nm}$ region, and the difference spectrum of Tyr26Ala with the wild type exhibited a positive exciton couplet centered at $227 \mathrm{~nm}$ (Figure S3B of the Supporting Information). Deletion of Trp66 gave a spectrum with a weak positive maximum at $238 \mathrm{~nm}$, with only $20 \%$ of the wild-type intensity, and the difference spectrum for Trp66Ala was a positive couplet comparable in magnitude to that for Tyr26Ala (Figure S3A of the 
Supporting Information). For the other mutants, the long-wavelength positive band persisted, with nearly constant contributions from Tyr26 and Trp66. The magnitude of the band was changed only slightly upon deletion of Trp60 or Tyr70 (Figure S3E,F of the Supporting Information). However, deletion of Tyr87 led to a 70\% increase in amplitude, whereas deletion of Trp156 led to a 50\% decrease (Figure S3C,D of the Supporting Information). These two side chains make significant but opposing contributions to the long-wavelength exciton band, despite their low fractional participation. Nevertheless, Tyr26 and Trp66 dominate the $232 \mathrm{~nm}$ exciton band, and any perturbation that eliminates this band must affect one or both of these side chains. Therefore, exciton theory applied to the PagP crystal structure has conclusively identified Tyr26 and Trp66 as the main interacting aromatic side chains responsible for the observed exciton couplet.

The structural relationship between the hydrocarbon ruler and the nondegenerate Tyr26Trp66 exciton pair is shown to indicate how the exciton effect arises from an interaction between $\pi \rightarrow \pi^{*}$ transitions with similar but distinct energies (Figure $6 \mathrm{~A}$ ). The ${ }^{1} \mathrm{~L}_{\mathrm{a}}$ and ${ }^{1} \mathrm{~B}_{\mathrm{b}}$ electric dipole transition moments in Tyr26 and Trp66, respectively, couple to give two exciton states separated by the splitting energy, $\Delta_{i j}=\left(\delta_{i j}^{2}+4^{2}\right)^{1 / 2}$, where $V_{i j} \delta_{i j}$ is the energy difference between the two transitions, $\sigma_{i}$ and $\sigma_{j}$, and $V_{i j}$ is the interaction (Davydov) energy (Figure 6B). Considering only the coupling between the Tyr26 ${ }^{1} \mathrm{~L}_{\mathrm{a}}$ band and the $\operatorname{Trp} 66{ }^{1} \mathrm{~B}_{\mathrm{b}}$ band, and using the monopole-monopole interaction energy for calculating the wavelengths and the rotational strengths, the resulting exciton couplet is predicted to be positive and to exhibit a peak-to-trough strength of $\sim 2500 \mathrm{deg} \mathrm{cm}^{2} \mathrm{dmol}^{-1}$ (Figure $6 \mathrm{C}$ ). The sign of an exciton couplet is defined in accordance with the long-wavelength (first) Cotton effect and will be reversed in the enantiomeric structure. In contrast to the degenerate exciton case (with two identical chromophores), where $\Delta_{i j}$ reduces to $2 V_{i j}$, the mixing of the Tyr $26{ }^{1} \mathrm{~L}_{\mathrm{a}}$ and Trp66 ${ }^{1} \mathrm{~B}_{\mathrm{b}}$ bands is incomplete. The Tyr $26{ }^{1} \mathrm{~L}_{\mathrm{a}}$ band dominates the long-wavelength Cotton effect, and the Trp66 ${ }^{1} \mathrm{~B}_{\mathrm{b}}$ band dominates the short-wavelength Cotton effect. The exciton couplet will disappear in CD when either $V_{i j}$ or the rotational strength $\left(R_{\mathrm{O}}\right)$, representing the area under the two Gaussian distributions, is zero (12). Although the pointdipole approximation for calculating $V_{i j}$ is only accurate when the interchromophore distance vector $R_{i j}$ is large compared to the dimensions of the interacting chromophores and is replaced in practice by a monopole (distributed dipole) approximation (19), it usefully illustrates how $V_{i j}$ is related to the electric dipole transition moment vectors for $\mu_{i}$ and $\mu_{j}$ (Figure 6D). The dot products dictate that $V_{i j}$ is maximized by parallel and minimized by orthogonal vector relationships. In contrast, the scalar triple product in $R_{\mathrm{O}}$ for a nondegenerate exciton interaction dictates that $R_{\mathrm{O}}$ is maximized by orthogonal and vanishes for parallel vector relationships (12). Theoretically, the exciton can be extinguished by any structural perturbation arising from a Gly88 substitution that induces parallel or orthogonal relationships from the oblique vector relationships normally found to exist between the Tyr26 ${ }^{1} \mathrm{~L}_{\mathrm{a}}$ and $\operatorname{Trp} 66{ }^{1} \mathrm{~B}_{\mathrm{b}}$ transitions.

\section{Experimental Exciton Analysis}

To experimentally validate the predicted Tyr26-Trp66 nondegenerate exciton in PagP, we constructed, purified, and analyzed the Tyr26Phe, Trp66Phe, and Trp66His mutants. Both Trp66 mutants failed to refold as assessed by SDS-PAGE (Figure 7A), which indicates that 
Trp66 is a critical determinant of PagP folding. The Trp66His and Trp66Phe mutants remained in solution after failing to refold in LDAO at $25{ }^{\circ} \mathrm{C}$ but precipitated after heating to $100{ }^{\circ} \mathrm{C}$; their far-UV CD spectra revealed negative ellipticity below $210 \mathrm{~nm}$ at $25^{\circ} \mathrm{C}$, but $218 \mathrm{~nm}$ negative ellipticity was induced at $92^{\circ} \mathrm{C}$ to a similar extent as observed previously for wild-type PagP at the same temperature (Figure S1C of the Supporting Information). This observation supports our suggestion that the residual ellipticity observed at high temperatures reflects intermolecular $\beta$-structure formed prior to precipitation. By following the loss of ellipticity at $202 \mathrm{~nm}$ and the formation of ellipticity at $218 \mathrm{~nm}$, we found the Trp66 mutants revealed that unfolded PagP in LDAO begins the transition to an aggregated state above $80{ }^{\circ} \mathrm{C}$ (Figure S1D of the Supporting Information).

The Tyr26Phe mutant refolded successfully, and its far-UV CD spectrum did not exhibit any positive $\mathrm{CD}$ in the $230 \mathrm{~nm}$ region, thus confirming the predicted contribution of Tyr 26 to the long-wavelength exciton band (Figure 7B). However, the negative band was red-shifted from 218 to $222 \mathrm{~nm}$, which indicates that the peptide backbone conformation is modulated by contributions from Tyr 26 because loss of the exciton prior to $\beta$-barrel unfolding at $80{ }^{\circ} \mathrm{C}$ (Figure 5C), or in the Gly88Cys mutant (Figure 4A), was not accompanied by a red shift. By following loss of the $222 \mathrm{~nm}$ negative $\mathrm{CD}$ band in Tyr26Phe PagP, we observed an $8{ }^{\circ} \mathrm{C}$ reduction in the thermal transition temperature when compared to the $218 \mathrm{~nm}$ negative $\mathrm{CD}$ band lost from wild-type PagP (Figure 7C); only the latter displays loss of the exciton in the $40-50{ }^{\circ} \mathrm{C}$ range, and an apparent contribution of Tyr26 to folding cooperativity is revealed by comparing the slopes of the two precipitation curves. Subtracting the Tyr26Phe far-UV CD spectrum from that for wild-type PagP reveals the exciton couplet (Figure 7D), but the peak-to-trough strength better matches the theoretical prediction (Figure 6C) when the Tyr26Phe spectrum is first blue-shifted manually back to $218 \mathrm{~nm}$ from $222 \mathrm{~nm}$.

Although the Trp66 mutants failed to refold in vitro, we could successfully purify folded Trp66Phe and Trp66His PagP when they were expressed in vivo with an intact signal peptide (Figure S2 of the Supporting Information) as described previously (21). The in vivofolded wild-type and Trp66 mutant PagP proteins appeared folded by both SDS-PAGE and far-UV CD criteria (Figure S2A,B of the Supporting Information). The far-UV CD spectra validate the predicted contribution of Trp66 to the nondegenerate exciton interaction by revealing the loss of positive ellipticity above $230 \mathrm{~nm}$ and the formation of a weaker negative ellipticity maximum at $218 \mathrm{~nm}$. In contrast to Tyr26Phe PagP, no red shift was associated with the loss of the exciton in the Trp66 mutants. The predicted dominance of the Tyr26 and Trp66 contributions to the long- and short-wavelength exciton bands, respectively (Figure S3A,B of the Supporting Information), appears to be validated by the experimental observations (Figure 7B and Figure S2B of the Supporting Information). The failure of the Trp66 mutants to fold in vitro is reflected in the instability associated with their reduced thermal unfolding temperature of $75^{\circ} \mathrm{C}$ compared with a temperature of $88{ }^{\circ} \mathrm{C}$ observed for the in vivo folded wild-type protein (Figure S2C of the Supporting Information). However, the Gly88Cys PagP mutant was successfully folded in vitro despite the fact it displays a thermal unfolding temperature of only $65{ }^{\circ} \mathrm{C}$ (Figure 4C). Periplasmic chaperones are known to assist the folding of outer membrane $\beta$-barrel proteins in E. coli and likely help to overcome the folding defect associated with the PagP Trp66 mutations (45). The observation of reduced thermal unfolding temperatures for both the Tyr26 (Figure 7C) and Trp66 (Figure 
S2C of the Supporting Information) PagP mutants suggests that destabilizing effects will likely be associated with proximal groups that perturb these aromatic side chains.

\section{Hydrocarbon Ruler Experiments}

The remarkable thermal stability of PagP in detergent micelles provides the destabilized Gly88Cys PagP mutant with sufficient residual stability to easily tolerate the temperature of $30{ }^{\circ} \mathrm{C}$ encountered in the PagP hydrocarbon ruler assay. The assays are performed using a suite of synthetic diacylphosphatidylcho-line donors that possess saturated acyl chains varying in length from 10 to 18 carbons in single-methylene unit increments (11). $\left[{ }^{32} \mathrm{P}\right] \mathrm{Kdo}_{2}$-lipid A (Figure 1A) is used as the acyl acceptor, and acylation is assessed by a TLC-based assay (Figure 8). All PagP derivatives that exhibit exciton couplets are able to select acyl chains of the length predicted by the hydrocarbon ruler hypothesis, and they do it with single-methylene unit resolution. Only Gly88Cys PagP, which lacks the exciton because of a local structural perturbation arising from its single sulfhydryl group, could not accommodate a single acyl chain of the predicted length. Rather, Gly88Cys PagP accommodated two acyl chains: one with the predicted length and one extended by an extra methylene unit.

\section{In Silico Mutagenesis}

Efforts to crystallize the PagP mutant proteins have so far not met with any success. Therefore, we opted to perform in silico mutagenesis and assess the conformational preferences of the substituted side chains by constrained simulated annealing molecular dynamics. The main features surrounding the floor of the hydrocarbon ruler in the wild-type PagP crystal structure are outlined in Figure 6A and given a different perspective in the right portion of Figure 8A. Here the LDAO molecule that occupies the hydrocarbon ruler has been removed, and the vacated space is outlined with a contoured shell. The position of Gly88 reveals that the pro-L hydrogen is directed toward the base of the hydrocarbon ruler and should direct any substituted amino acid side chain into the base of the cavity. Flanking this site are Tyr26 and Trp66, which approach each other in a geometric relationship that affords an exciton delocalization of the two chromophore-excited states. The amino acid substitutions associated with expression of both the exciton couplet and single-methylene unit resolution were found to advance into the hydrocarbon ruler floor (Figure 8B,D,E), but the Cys sulfhydryl group was found to recede downward and induce a $1 \AA$ shift in the position of the indole ring of Trp66, which alters its geometric relationship with respect to Tyr26 (Figure 8C). Another possible source of perturbation of the local structure of the enzyme is the presence of a weak electrostatic interaction between the sulfhydryl group and the hydroxyl group of Tyr26, which is $4 \AA$ away. These predictions suggest that the loss of the exciton in Gly88Cys PagP results from a local perturbation of Trp66 and/or Tyr26 arising from the downward orientation of the Cys sulfhydryl group, which also serves to expand the hydrocarbon ruler and allow the enzyme to accommodate an additional acyl chain with one extra methylene unit. We propose that the Gly88Cys PagP hydrocarbon ruler is tailored to optimally accommodate an acyl chain that lies somewhere between $\mathrm{C} 14$ and C15 and is thus capable of using both. 
The thioether (sulfide) bond introduced into Gly88Cys- $S$-methyl PagP is a decidedly hydrophobic entity (46) that is expected to occupy the hydrophobic pocket as predicted by the hydrocarbon ruler hypothesis. In vitro, this mutant selects the expected 13-carbon saturated acyl chain with single-methylene unit resolution (Figure 8D), and it exhibits a full exciton couplet (Figure 4A). Although the simulated annealing calculations fall short of exhaustively sampling conformational space, the annealed conformations of Gly88Met suggest that this side chain spans a wider spatial distribution than the other mutants of Gly88 (Figure 8A-E). This observation is consistent with the fact that Gly88Met PagP, while preferentially selective for the expected 12-carbon saturated acyl chain, also exhibits residual ability to bind an acyl chain with one extra methylene unit. These observations might reflect a positional preference within the hydrocarbon ruler environment for the inherent conformational flexibility around the thioether $\mathrm{CH}_{3} \mathrm{~S}-\mathrm{CH}_{2}$ torsional unit and/or dispersion forces associated with the thioether sulfur atom (46).

Despite our experimental observations that the exciton is retained in all mutants except Gly88Cys PagP, exciton calculations using structures from simulated annealing did not predict its presence in any of them. Even for wild-type PagP, the simulated annealing results are not predicted to have an exciton. This finding suggests that the $\mathrm{X}$-ray conformation is a better representation of the conformational ensemble of the protein than the locally relaxed conformations obtained from our simulated annealing calculations. Obtaining more realistic conformations of the mutants would require letting the enzyme relax and reach thermal equilibrium in explicit membrane and solvent. Nevertheless, the high-temperature simulated annealing calculations are a first step in modeling the local conformational preferences of the mutant side chains. These preferences are qualitatively different for the Cys mutant, which is consistent with the measured extinction of the exciton.

\section{DISCUSSION}

Excitons in proteins can arise from through-space interactions between the excited states of neighboring Trp and/or Tyr aromatic chromophores. Although such excitons are by no means present in every protein structure, they are more common than is widely appreciated (19). Exciton couplets observed in some proteins have been previously employed to analyze protein structure $(47,48)$, but efforts to identify the residues actually responsible for the exciton interaction, and to employ them as intrinsic probes for monitoring structure-function relationships, have been rare. An exciton couplet formed by Trp172 and Trp215 in chymotrypsinogen and chymotrypsin was used to demonstrate conversion of the active enzyme conformation to the zymogen conformation at high $\mathrm{pH}$ and to show that the diisopropyl fluorophosphate-inactivated enzyme does not undergo this transition (49). However, the excitonic origin of the far-UV features in the CD spectra of chymotrypsinogen and chymotrypsin was not demonstrated until much later (19). Exciton coupling between Trp47 and Trp74 in E. coli dihydrofolate reductase was identified as the source of the first transient that can be detected by stopped flow in the refolding of the urea-denatured enzyme (50). More recently, a Gly95Ala mutation has been shown to abolish the Trp-Trp exciton, whereas binding of methotrexate restores it (51). Given the forecasted output of current structural proteomics consortia, it is likely that the pool of proteins exhibiting clearly discernible exciton couplets will continue to grow rapidly into the future. Such knowledge 
will provide investigators with highly sensitive probes for monitoring the functional effects of locally introduced structural alterations.

A case in point is revealed by our current study of PagP, which has a number of favorable features that made the study possible. (1) The compact $\beta$-barrel structure of PagP produces a relatively weak backbone $C D$ that makes obvious the overlapping exciton couplet. (2) PagP can resolve methylene units in the acyl chains of its lipid substrate by using a molecular measuring device known as a hydrocarbon ruler, the floor of which is located in the proximity of the interacting exciton partners. (3) PagP is an extremely stable small protein that can be unfolded and refolded in vitro, enabling the transient exposure of buried functional groups for chemical modification. The fact that $\mathrm{PagP}$ is an integral membrane protein makes these favorable features all the more remarkable. Consequently, PagP beautifully demonstrates both the sensitivity of the exciton and how it can be employed as a spectroscopic probe to monitor a local structural perturbation.

The PagP hydrocarbon ruler was identified in a prior X-ray structure determination (11) and validated in that study by using enzyme that had been purified directly from membranes (21). However, the LDAO detergent used to purify the enzyzme is a competitive inhibitor (11) and must be exchanged by dilution of the enzyme into a reaction cocktail that includes $n$-dodecyl $\beta$-D-maltoside or another detergent that supports PagP activity (21). While PagP purified directly from membranes is obtained at $\sim 1 \mathrm{mg} / \mathrm{mL}$ (21), PagP can also be expressed without its $\mathrm{N}$-terminal signal peptide, purified in an unfolded state, and reliably refolded in LDAO to reach a concentration of $>10 \mathrm{mg} / \mathrm{mL}(10,11)$. Consequently, LDAO can be removed more effectively by dilution when using refolded PagP, which gives more reliable results in the enzyme assays. By using refolded PagP derivatives in this investigation, we observed for the first time that Gly88 substitutions, with the exception of the Cys mutation, modulate hydrocarbon ruler acyl-chain selection with methylene unit precision.

The predicted interactions of the Cys sulfhydryl group with the Trp66 and Tyr26 aromatic side chains can explain our main experimental observations that Gly88Cys PagP is both devoid of the exciton and compromised in terms of acyl-chain selection. Our simulated annealing experiments demonstrate that the amino acid substitutions observed experimentally to retain the exciton are advancing upward into the hydrocarbon ruler floor, while the one side chain that is able to recede downward (Cys) is observed to extinguish the exciton. The question of why the Cys sulfhydryl group would prefer the position between Tyr26 and Trp66 instead of inside the hydrophobic hydrocarbon ruler pocket remains. The hydrocarbon ruler floor in PagP marks the boundary between the upper hydrophobic and lower polar interior regions of the $\beta$-barrel (11), which might indicate that the Cys sulfhydryl group has an inherent tendency to seek out a more polar microenvironment. Hydrophobicity scales derived primarily from a-helical transmembrane domains typically identify Cys as being hydrophobic (52), but Cys in an a-helix normally donates a hydrogen bond to the carbonyl oxygen atom of the preceding peptide bond (53). In contrast, the sulfhydryl group of Gly88Cys PagP is forced into a $\beta$-structured conformation where it is faced above with nonpolar and below with polar environments. In the absence of a suitable hydrogen bond acceptor, the Cys sulfhydryl group appears to have rotated about its $\chi_{1}$ dihedral angle to establish a weak electrostatic interaction with the Tyr26 hydroxyl group 
and/or a so-called $\pi$ (aromatic)-lone pair (sulfur) attraction with Trp66 (54). The polarizability of the sulfur atom and the acidity of the sulfhydryl group are reported to promote its interaction with aromatic partners (55). Although our force field contains only partial point charges on each nucleus, which is but a rough approximation to the electronic distribution associated with (pure and hybrid) p orbitals, the force field may be capable of capturing these effects qualitatively.

The lactose permease provides an example of an a-helical transmembrane protein in which substitutions of Cys for Gly have had unpredictable effects on protein stability. The replacement of Cys154 with Gly within a transmembrane domain of the lactose permease has been shown to have stabilizing effects that are incompatible with active transport but necessary to obtain crystals for determining the structure by X-ray diffraction $(56,57)$. Only Cys at position 154 was capable of introducing a local instability that was necessary for normal transport (58). The lactose permease in this region includes local distortions of helical conformation and close packing interactions with several aromatic partners. Perhaps the unusual physical properties associated with Cys154 in lactose permease have in common with Gly88Cys PagP the need to establish interactions with aromatic side chains. Clearly, the PagP hydrocarbon ruler affords unique opportunities to evaluate the physical forces at work in determining membrane protein stability. Our ability to enzymatically synthesize endotoxin analogues with defined acyl-chain substitutions might also reveal pharmacologically interesting derivatives, because acyl-chain length is known to be an important factor in determining endotoxin structure-activity relationships (59).

\section{Supplementary Material}

Refer to Web version on PubMed Central for supplementary material.

\section{Acknowledgments}

We gratefully acknowledge Walid Houry and Avi Chakrabartty (University of Toronto) for sharing their CD spectrometers, Anthony Mittermaier (now at McGill University, Montreal, QC) for setting up the initial PagP structure for molecular dynamics studies, and Fraser Hof (University of Victoria, Victoria, BC), Charles Deber (University of Toronto), and Richard and Raquel Epand (McMaster University) for helpful discussions.

\section{References}

1. Vance, DE., Vance, JE. Biochemistry of Lipids, Lipoproteins, and Membranes. Elsevier; Amsterdam: 2002.

2. Dowhan W. Molecular basis for membrane phospholipid diversity: Why are there so many lipids? Annu Rev Biochem. 1997; 66:199-232. [PubMed: 9242906]

3. Zhang YM, White SW, Rock CO. Inhibiting bacterial fatty acid synthesis. J Biol Chem. 2006; 281:17541-17544. [PubMed: 16648134]

4. Bracey MH, Cravatt BF, Stevens RC. Structural commonalities among integral membrane enzymes. FEBS Lett. 2004; 567:159-165. [PubMed: 15178315]

5. Long SB, Casey PJ, Beese LS. Cocrystal structure of protein farnesyltransferase complexed with a farnesyl diphosphate substrate. Biochemistry. 1998; 37:9612-9618. [PubMed: 9657673]

6. Wyckoff TJ, Lin S, Cotter RJ, Dotson GD, Raetz CR. Hydrocarbon rulers in UDP- $N$ acetylglucosamine acyltransferases. J Biol Chem. 1998; 273:32369-32372. [PubMed: 9829962]

7. White SH, Ladokhin AS, Jayasinghe S, Hristova K. How membranes shape protein structure. J Biol Chem. 2001; 276:32395-32398. [PubMed: 11432876] 
8. Snijder HJ, Ubarretxena-Belandia I, Blaauw M, Kalk KH, Verheij HM, Egmond MR, Dekker N, Dijkstra BW. Structural evidence for dimerization-regulated activation of an integral membrane phospholipase. Nature. 1999; 401:717-721. [PubMed: 10537112]

9. Rutten L, Geurtsen J, Lambert W, Smolenaers JJ, Bonvin AM, de Haan A, van der Ley P, Egmond MR, Gros P, Tommassen J. Crystal structure and catalytic mechanism of the LPS 3- $O$-deacylase PagL from Pseudomonas aeruginosa. Proc Natl Acad Sci USA. 2006; 103:7071-7076. [PubMed: 16632613]

10. Hwang PM, Choy WY, Lo EI, Chen L, Forman-Kay JD, Raetz CR, Prive GG, Bishop RE, Kay LE. Solution structure and dynamics of the outer membrane enzyme PagP by NMR. Proc Natl Acad Sci USA. 2002; 99:13560-13565. [PubMed: 12357033]

11. Ahn VE, Lo EI, Engel CK, Chen L, Hwang PM, Kay LE, Bishop RE, Prive GG. A hydrocarbon ruler measures palmitate in the enzymatic acylation of endotoxin. EMBO J. 2004; 23:2931-2941. [PubMed: 15272304]

12. Harada, N., Nakanishi, K. Circular dichroic spectroscopy: Exciton coupling in organic stereochemistry. University Science Books; Mill Valley, CA: 1983.

13. Schellman JA. Symmetry rules for optical rotation. Acc Chem Res. 1968; 1:144-151.

14. Davydov, AS. Theory of molecular excitons. Translated from Russian by Stephen B. Dresner. Plenum Press; New York: 1971. New American ed

15. Woody RW. Circular dichroism. Methods Enzymol. 1995; 246:34-71. [PubMed: 7538625]

16. Woody RW. Contributions of tryptophan side chains to the far-ultraviolet circular dichroism of proteins. Eur Biophys J. 1994; 23:253-262. [PubMed: 7805627]

17. Sreerama N, Woody RW. On the analysis of membrane protein circular dichroism spectra. Protein Sci. 2004; 13:100-112. [PubMed: 14691226]

18. Sreerama N, Woody RW. Computation and analysis of protein circular dichroism spectra. Methods Enzymol. 2004; 383:318-351. [PubMed: 15063656]

19. Grishina IB, Woody RW. Contributions of tryptophan side chains to the circular dichroism of globular proteins: Exciton couplets and coupled oscillators. Faraday Discuss. 1994:245-262. [PubMed: 7549540]

20. Bishop RE. The lipid A palmitoyltransferase PagP: Molecular mechanisms and role in bacterial pathogenesis. Mol Microbiol. 2005; 57:900-912. [PubMed: 16091033]

21. Bishop RE, Gibbons HS, Guina T, Trent MS, Miller SI, Raetz CR. Transfer of palmitate from phospholipids to lipid A in outer membranes of Gram-negative bacteria. EMBO J. 2000; 19:50715080. [PubMed: 11013210]

22. Kamio Y, Nikaido H. Outer membrane of Salmonella typhimurium: Accessibility of phospholipid head groups to phospholipase $\mathrm{c}$ and cyanogen bromide activated dextran in the external medium. Biochemistry. 1976; 15:2561-2570. [PubMed: 820368]

23. Nikaido H. Molecular basis of bacterial outer membrane permeability revisited. Microbiol Mol Biol Rev. 2003; 67:593-656. [PubMed: 14665678]

24. Guo L, Lim KB, Poduje CM, Daniel M, Gunn JS, Hackett M, Miller SI. Lipid A acylation and bacterial resistance against vertebrate antimicrobial peptides. Cell. 1998; 95:189-198. [PubMed: 9790526]

25. Kawasaki K, Ernst RK, Miller SI. 3-O-Deacylation of lipid A by PagL, a PhoP/PhoQ-regulated deacylase of Salmonella typhimurium, modulates signaling through toll-like receptor 4. J Biol Chem. 2004; 279:20044-20048. [PubMed: 15014080]

26. Hwang PM, Bishop RE, Kay LE. The integral membrane enzyme PagP alternates between two dynamically distinct states. Proc Natl Acad Sci USA. 2004; 101:9618-9623. [PubMed: 15210985]

27. Jia W, Zoeiby AE, Petruzziello TN, Jayabalasingham B, Seyedirashti S, Bishop RE. Lipid trafficking controls endotoxin acylation in outer membranes of Escherichia coli. J Biol Chem. 2004; 279:44966-44975. [PubMed: 15319435]

28. Gill SC, von Hippel PH. Calculation of protein extinction coefficients from amino acid sequence data. Anal Biochem. 1989; 182:319-326. [PubMed: 2610349]

29. Heinrikson RL. The selective $S$-methylation of sulfhydryl groups in proteins and peptides with methyl-p-nitrobenzene-sulfonate. J Biol Chem. 1971; 246:4090-4096. [PubMed: 5105446] 
30. Whitelegge JP, le Coutre J, Lee JC, Engel CK, Prive GG, Faull KF, Kaback HR. Toward the bilayer proteome, electrospray ionization-mass spectrometry of large, intact transmembrane proteins. Proc Natl Acad Sci USA. 1999; 96:10695-10698. [PubMed: 10485888]

31. Smith PK, Krohn RI, Hermanson GT, Mallia AK, Gartner FH, Provenzano MD, Fujimoto EK, Goeke NM, Olson BJ, Klenk DC. Measurement of protein using bicinchoninic acid. Anal Biochem. 1985; 150:76-85. [PubMed: 3843705]

32. Edelhoch H. Spectroscopic determination of tryptophan and tyrosine in proteins. Biochemistry. 1967; 6:1948-1954. [PubMed: 6049437]

33. Pace CN, Vajdos F, Fee L, Grimsley G, Gray T. How to measure and predict the molar absorption coefficient of a protein. Protein Sci. 1995; 4:2411-2423. [PubMed: 8563639]

34. Woody RW, Sreerama N. Comment on 'Improving protein circular dichroism calculations in the far-ultraviolet through reparameterizing the amide chromophore' [J. Chem Phys 109, 782 (1998)]. J Chem Phys. 1999; 111:2844-2845.

35. Kanipes MI, Lin S, Cotter RJ, Raetz CR. $\mathrm{Ca}^{2+}$-induced phosphoethanolamine transfer to the outer 3-deoxy-D-manno-octulosonic acid moiety of Escherichia coli lipopolysaccharide. A novel membrane enzyme dependent upon phosphatidyl-ethanolamine. J Biol Chem. 2001; 276:11561163. [PubMed: 11042192]

36. Lee CH, Tsai CM. Quantification of bacterial lipopolysaccharides by the purpald assay: Measuring formaldehyde generated from 2-keto-3-deoxyoctonate and heptose at the inner core by periodate oxidation. Anal Biochem. 1999; 267:161-168. [PubMed: 9918668]

37. Feller SE, MacKerell AD. An improved empirical potential energy function for molecular simulations of phospholipids. J Phys Chem B. 2000; 104:7510-7515.

38. Jorgensen WL, Chandrasekhar J, Madura JD, Impey RW, Klein ML. Comparison of simple potential functions for simulating liquid water. J Chem Phys. 1983; 79:926-935.

39. Brooks BR, Bruccoleri RE, Olafson BD, States DJ, Swaminathan S, Karplus M. Charmm: A Program for Macromolecular Energy, Minimization, and Dynamics Calculations. J Comput Chem. 1983; 4:187-217.

40. MacKerell AD, Bashford D, Bellott M, Dunbrack RL, Evanseck JD, Field MJ, Fischer S, Gao J, Guo H, Ha S, Joseph-McCarthy D, Kuchnir L, Kuczera K, Lau FTK, Mattos C, Michnick S, Ngo T, Nguyen DT, Prodhom B, Reiher WE, Roux B, Schlenkrich M, Smith JC, Stote R, Straub J, Watanabe M, Wiorkiewicz-Kuczera J, Yin D, Karplus M. All-atom empirical potential for molecular modeling and dynamics studies of proteins. J Phys Chem B. 1998; 102:3586-3616. [PubMed: 24889800]

41. Humphrey W, Dalke A, Schulten K. VMD: Visual molecular dynamics. J Mol Graphics. 1996; 14:33-38. 27-28.

42. Smart OS, Goodfellow JM, Wallace BA. The pore dimensions of gramicidin A. Biophys J. 1993; 65:2455-2460. [PubMed: 7508762]

43. DeLano, WL. The PyMOL Molecular Graphics System. DeLano Scientific; San Carlos, CA: 2002.

44. Saxena VP, Wetlaufer DB. A new basis for interpreting the circular dichroic spectra of proteins. Proc Natl Acad Sci USA. 1971; 68:969-972. [PubMed: 5280530]

45. Mogensen JE, Otzen DE. Interactions between folding factors and bacterial outer membrane proteins. Mol Microbiol. 2005; 57:326-346. [PubMed: 15978068]

46. Gellman SH. On the role of methionine residues in the sequence-independent recognition of nonpolar protein surfaces. Biochemistry. 1991; 30:6633-6636. [PubMed: 2065050]

47. Gasymov OK, Abduragimov AR, Yusifov TN, Glasgow BJ. RET and anisotropy measurements establish the proximity of the conserved Trp17 to Ile98 and Phe99 of tear lipocalin. Biochemistry. 2002; 41:8837-8848. [PubMed: 12102626]

48. Nakao M, Maki K, Arai M, Koshiba T, Nitta K, Kuwajima K. Characterization of kinetic folding intermediates of recombinant canine milk lysozyme by stopped-flow circular dichroism. Biochemistry. 2005; 44:6685-6692. [PubMed: 15850402]

49. McConn J, Fasman GD, Hess GP. Conformation of the high $\mathrm{pH}$ form of chymotrypsin. J Mol Biol. 1969; 39:551-562. [PubMed: 5357213] 
50. Kuwajima K, Garvey EP, Finn BE, Matthews CR, Sugai S. Transient intermediates in the folding of dihydrofolate reductase as detected by far-ultraviolet circular dichroism spectroscopy. Biochemistry. 1991; 30:7693-7703. [PubMed: 1868049]

51. Svensson AK, O'Neill JC Jr, Matthews CR. The coordination of the isomerization of a conserved non-prolyl cis peptide bond with the rate-limiting steps in the folding of dihydrofolate reductase. $\mathrm{J}$ Mol Biol. 2003; 326:569-583. [PubMed: 12559923]

52. Bowie JU. Solving the membrane protein folding problem. Nature. 2005; 438:581-589. [PubMed: 16319877]

53. Gray TM, Matthews BW. Intrahelical hydrogen bonding of serine, threonine and cysteine residues within a-helices and its relevance to membrane-bound proteins. J Mol Biol. 1984; 175:75-81. [PubMed: 6427470]

54. Duan G, Smith VH Jr, Weaver DF. Characterization of aromatic-thiol $\pi$-type hydrogen bonding and phenylalanine-cysteine side chain interactions through $a b$ initio calculations and protein database analyses. Mol Phys. 2001; 99:1689-1699.

55. Meyer EA, Castellano RK, Diederich F. Interactions with aromatic rings in chemical and biological recognition. Angew Chem, Int Ed. 2003; 42:1210-1250.

56. Smirnova IN, Kaback HR. A mutation in the lactose permease of Escherichia coli that decreases conformational flexibility and increases protein stability. Biochemistry. 2003; 42:3025-3031. [PubMed: 12627968]

57. Abramson J, Smirnova I, Kasho V, Verner G, Kaback HR, Iwata S. Structure and mechanism of the lactose permease of Escherichia coli. Science. 2003; 301:610-615. [PubMed: 12893935]

58. Ermolova NV, Smirnova IN, Kasho VN, Kaback HR. Interhelical packing modulates conformational flexibility in the lactose permease of Escherichia coli. Biochemistry. 2005; 44:7669-7677. [PubMed: 15909981]

59. Stover AG, Da Silva Correia J, Evans JT, Cluff CW, Elliott MW, Jeffery EW, Johnson DA, Lacy MJ, Baldridge JR, Probst P, Ulevitch RJ, Persing DH, Hershberg RM. Structure-activity relationship of synthetic toll-like receptor 4 agonists. J Biol Chem. 2004; 279:4440-4449. [PubMed: 14570885] 

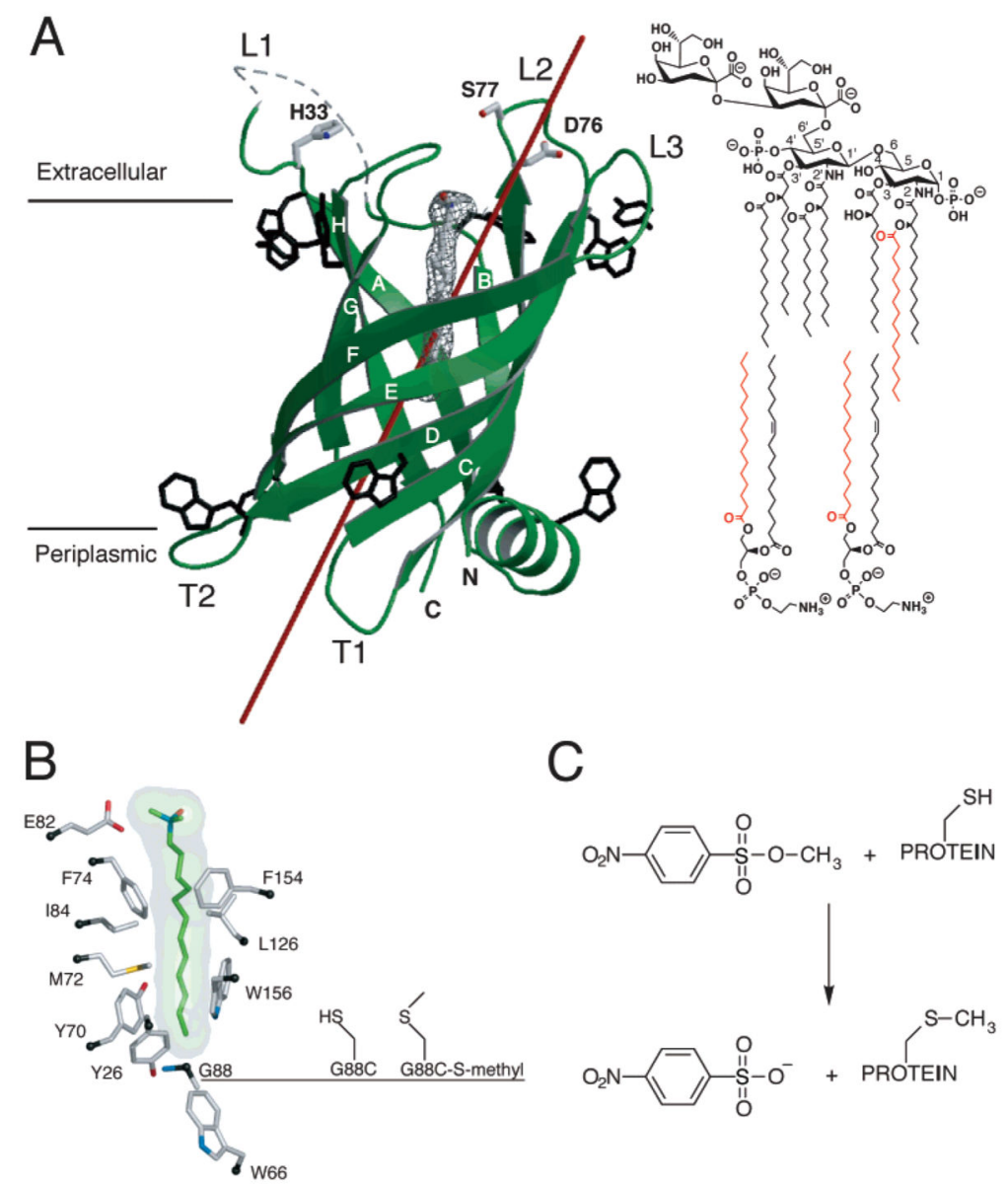

C

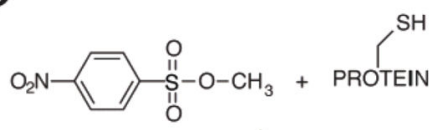

Figure 1.

Site-specific chemical modification of the PagP hydrocarbon ruler. (A) PagP resides in the E. coli outer membrane, where LPS (shown as $\mathrm{Kdo}_{2}$-lipid A) lines the outer leaflet and phospholipids line the inner leaflet. A bound LDAO detergent molecule resides within the PagP hydrocarbon ruler, which has lateral access to lipid substrates in the outer leaflet. PagP transfers a palmitate chain (red) from a phospholipid to lipid A and depends on the aberrant migration of phospholipids into the outer leaflet. (B) The hydrocarbon ruler dimensions determine PagP's ability to strictly select a 16-carbon saturated palmitate chain. Substitution of Gly88 at the base of the hydrocarbon ruler can cause PagP to select shorter acyl chains. (C) Strategy for site-specific S-methylation of Gly88Cys PagP using MNBS. 


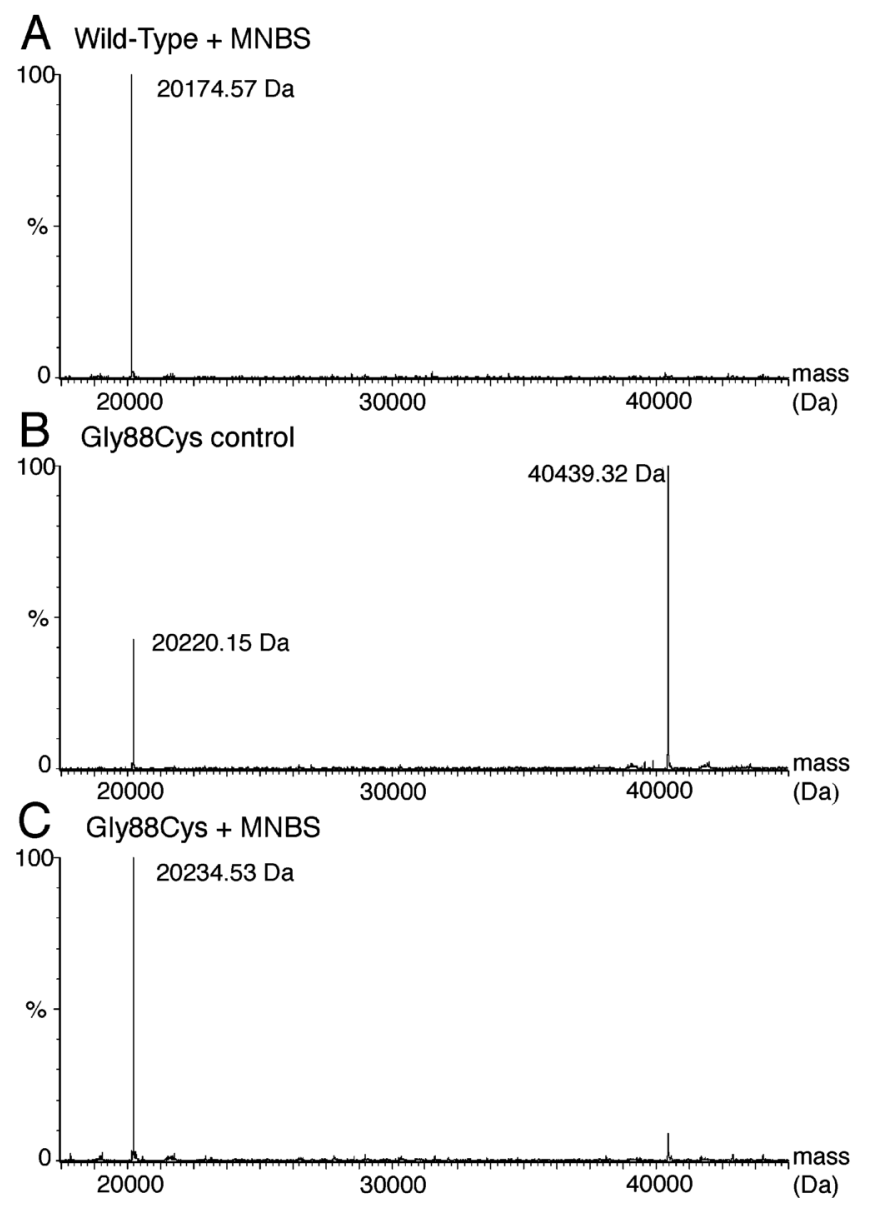

Figure 2.

ESI-MS confirmation of Gly88Cys-S-methyl PagP. (A) Wild-type PagP treated with MNBS exhibits a single mass that corresponds to an unmodified monomeric species. (B) In the absence of MNBS, Gly88Cys PagP exhibits two masses that correspond to an unmodified monomer and a disulfide-linked dimer. (C) MNBS treatment of Gly88Cys PagP results in a 14 Da mass increase for the monomeric species and a loss of the disulfide-linked dimer. 


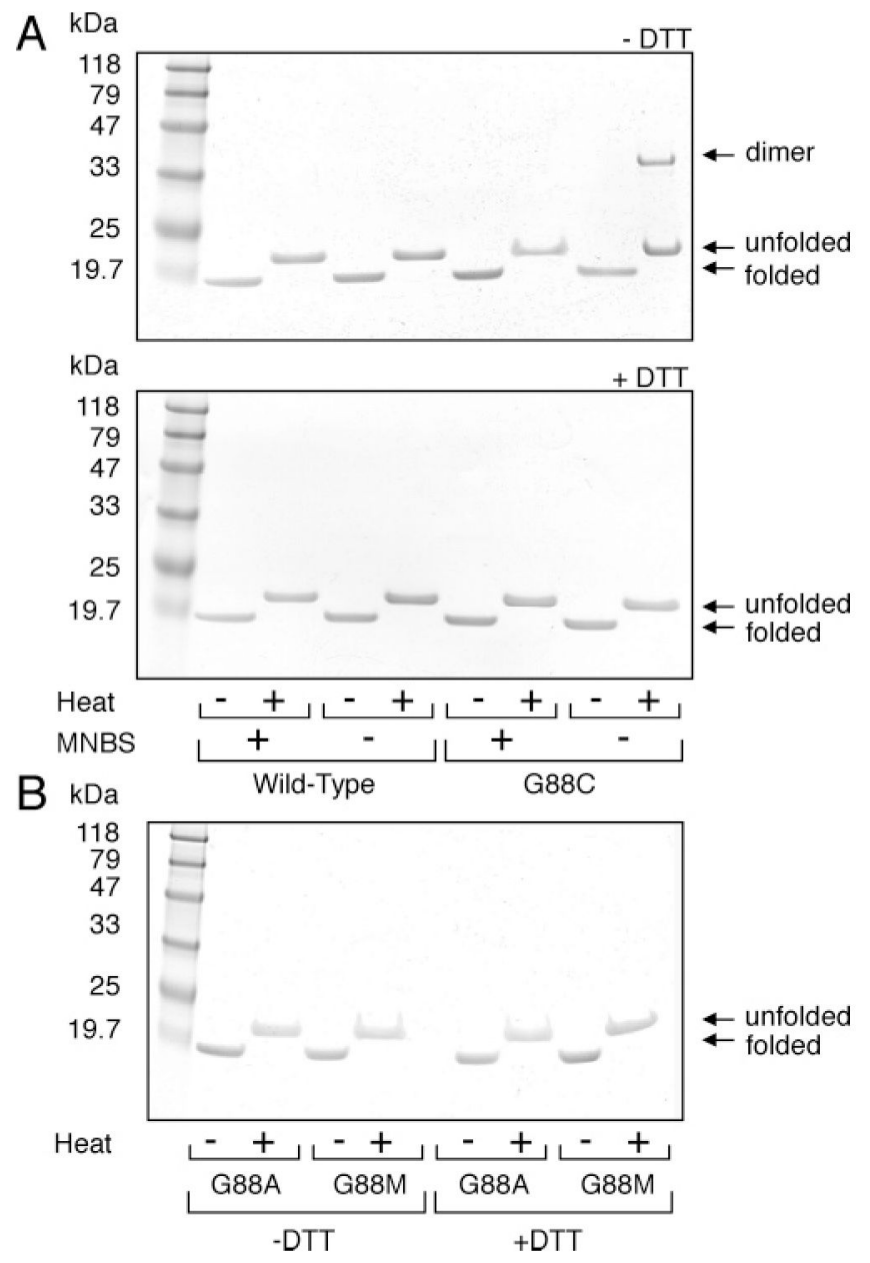

Figure 3.

SDS-PAGE analysis of PagP refolding. PagP requires heat treatment to become denatured via SDS-PAGE and migrates anomalously fast in the absence of heat treatment. (A) Analysis of wild-type and Gly88Cys PagP under reducing and nonreducing conditions, in the presence and absence of heat treatment, and with or without prior exposure to MNBS. (B) Analysis of Gly88Ala and Gly88Met PagP as described above, but without exposure to MNBS. 

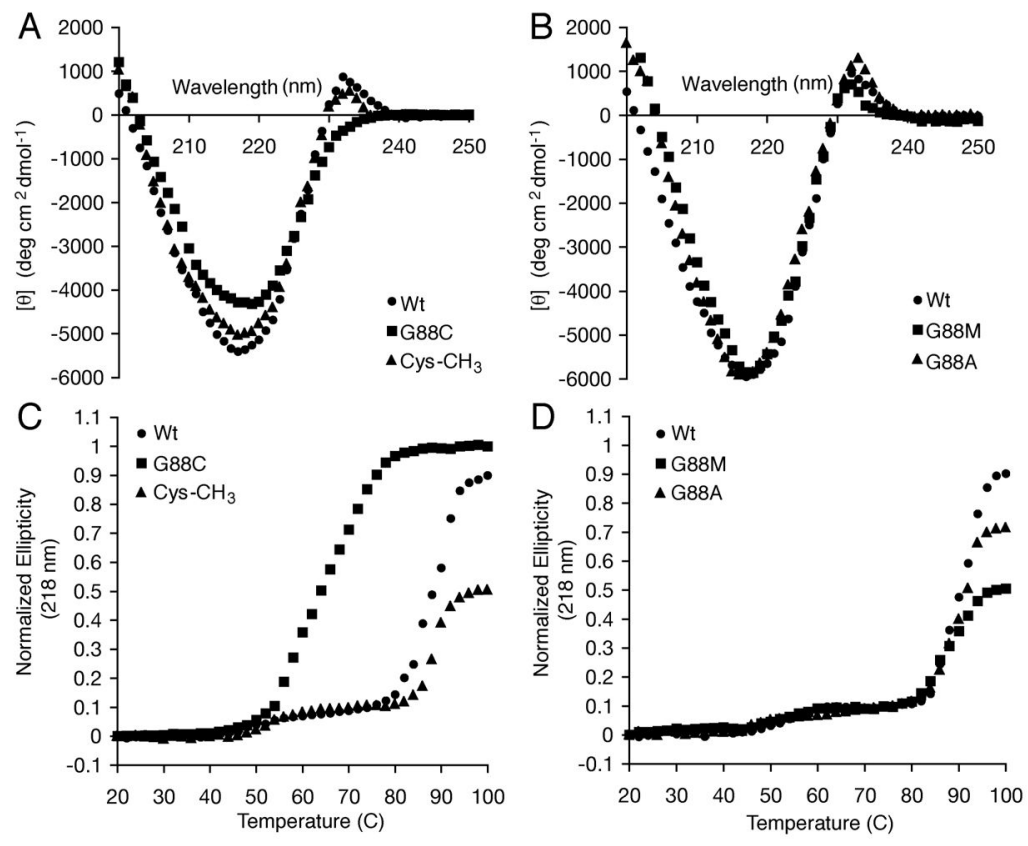

Figure 4.

Spectroscopic analysis of refolded PagP variants and evaluation of thermal stability. (A and B) Far-UV CD spectra of refolded PagP variants. (C and D) Thermal unfolding profiles of refolded PagP variants assessed by following the loss of the negative ellipticity maximum at $218 \mathrm{~nm}$ observed in panels A and B. 


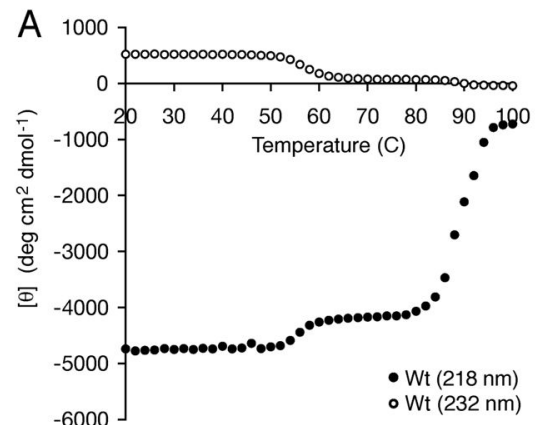

B
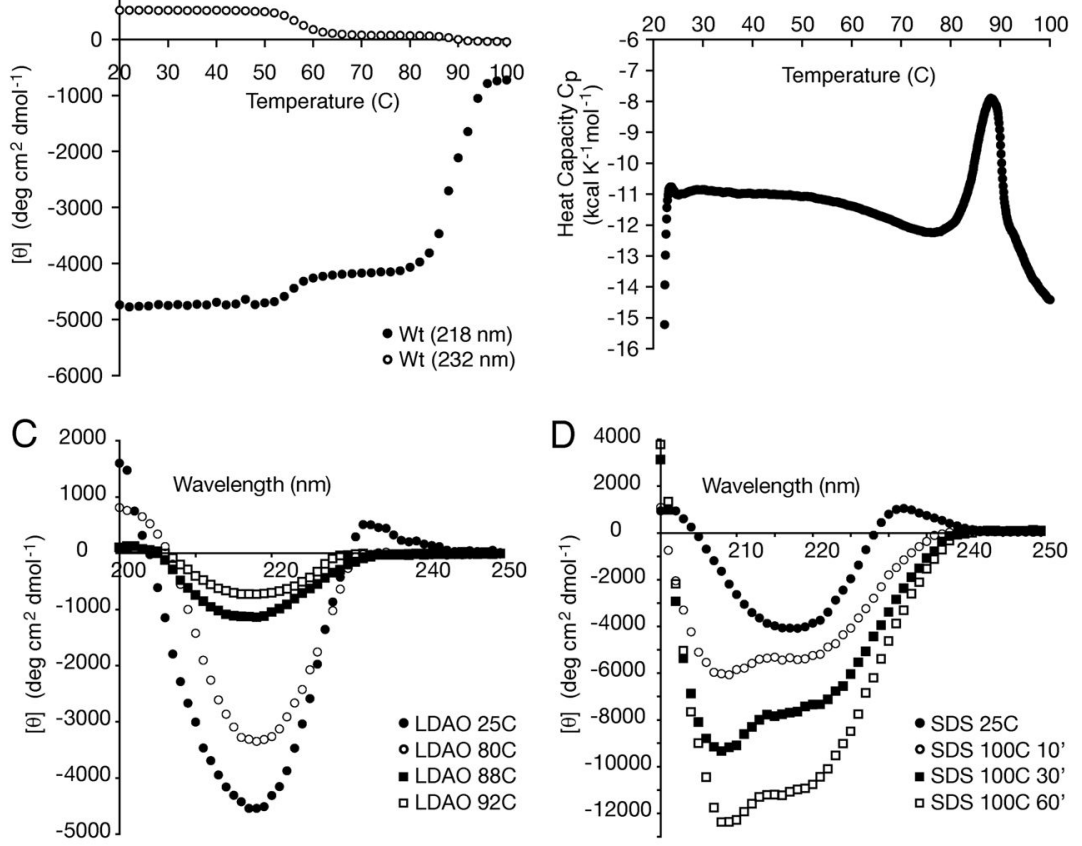

Figure 5.

Secondary structure associated with thermal unfolding of wild-type PagP. (A) Thermal unfolding profile of refolded wild-type PagP assessed by following the loss of the ellipticities at 218 and $232 \mathrm{~nm}$. (B) Thermal unfolding profile of wild-type PagP assessed by DSC. (C and D) Far-UV CD spectra of wild-type PagP refolded in LDAO and recorded at various points along the thermal unfolding profile after a $15 \mathrm{~min}$ equilibration (C) and in the presence of $1 \%$ SDS as a function of the time of incubation at $100{ }^{\circ} \mathrm{C}(\mathrm{D})$. 
A

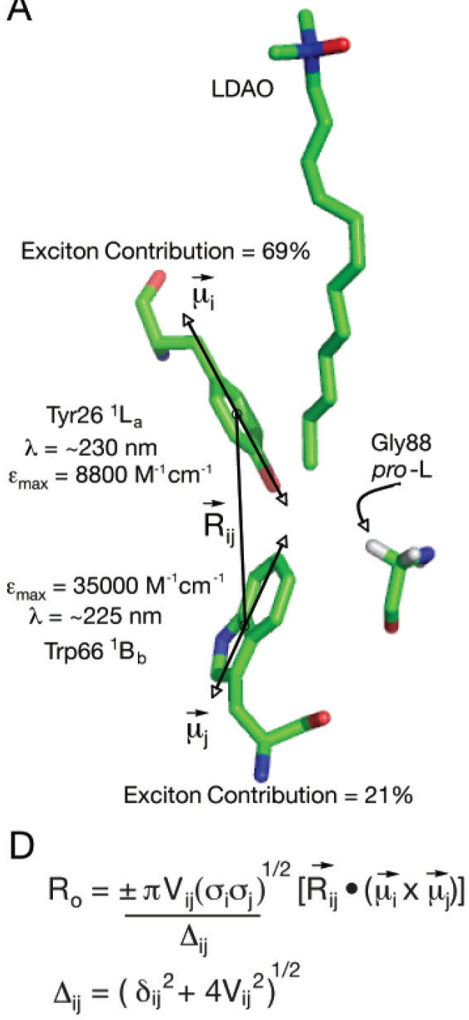

B

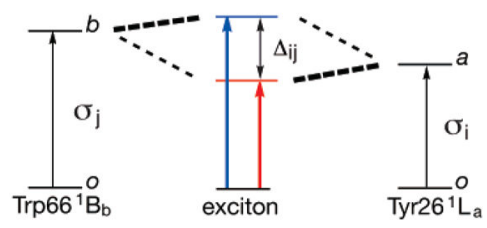

C

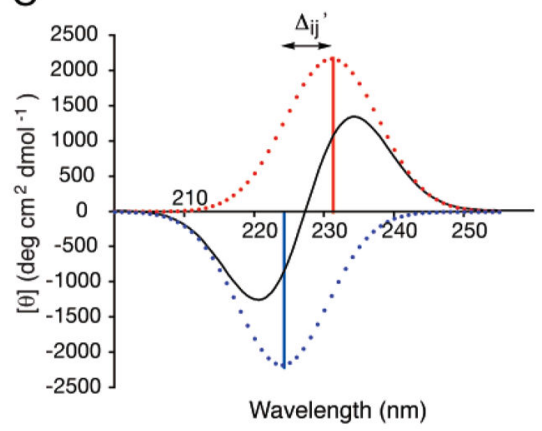

$V_{i j} \approx \frac{\left(\vec{\mu}_{i} \bullet \vec{\mu}_{j}\right)}{R_{i j}}-\frac{3\left(\overrightarrow{\mu_{i}} \bullet \vec{R}_{i j}\right)\left(\vec{\mu}_{j} \bullet \vec{R}_{i j}\right)}{R_{i j}{ }^{5}}$

$\delta_{i j}=\left(\sigma_{\mathrm{j}}-\sigma_{\mathrm{i}}\right)$

Figure 6.

Theoretical analysis of a nondegenerate exciton interaction in PagP. (A) Structural relationships between the PagP hydrocarbon ruler, emphasizing the LDAO molecule and the pro-L hydrogen of Gly88, and the exciton interaction between Tyr26 and Trp66. The polarization axes for the interacting Tyr26 ${ }^{1} \mathrm{~L}_{\mathrm{a}}\left(\mu_{i}\right)$ and $\operatorname{Trp} 661 \mathrm{~B}_{\mathrm{b}}\left(\mu_{j}\right)$ electric dipole transition moment vectors are shown to emphasize their relationships with the interchromophore distance vector $R_{i j}$. Key absorption parameters and the calculated exciton contribution to the wild-type PagP far-UV CD spectrum are also shown. (B) The $\pi \rightarrow \pi^{*}$ transitions from ground states $o$ to excited states $a$ (for Tyr26 ${ }^{1} \mathrm{~L}_{\mathrm{a}}$ ) or $b$ (for $\operatorname{Trp} 66{ }^{1} \mathrm{~B}_{\mathrm{b}}$ ) are split by a nondegenerate exciton interaction into two new exciton states, which generate $\mathrm{CD}$ Cotton effects equal in magnitude, opposite in sign, and separated by the splitting energy $\Delta_{i j}$. This splitting energy is given by $\left(\delta_{i j}^{2}+4 V_{i j}^{2}\right)^{1 / 2}$, where $\delta_{i j}\left(=\sigma_{j}-\sigma_{i}\right)$ is the difference in the transition energies of the two chromophores and $V_{i j}$ is the energy of interaction between the transition moments. Tyr26 and Trp66 each dominate the low-energy (red) and high-energy (blue) exciton states, respectively. (C) The exciton couplet (solid line) calculated from the Tyr26-Trp66 exciton interaction is the resultant of the two exciton-split CD Cotton effects (red and blue dotted curves), which are separated on the wavelength scale by $\Delta_{i j}{ }^{\prime}$, the wavelength equivalent of $\Delta_{i j}$ (D) The theoretical rotational strengths $\left(R_{\mathrm{O}}\right)$ of nondegenerate exciton split CD Cotton effects are proportional to $V_{i j}$, $\Delta_{i j}$, and a scalar triple product involving the vector connecting the centers of the two transitions and the dipole transition moments. $V_{i j}$ can be approximated by the point-dipole approximation, but a more exact method is used in calculating the spectra shown here. 
A

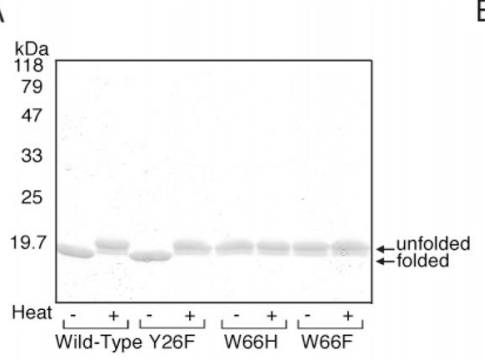

C

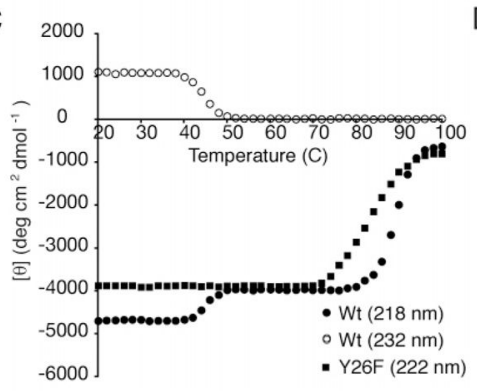

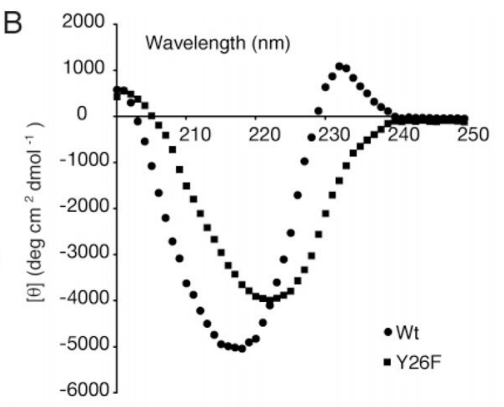

D

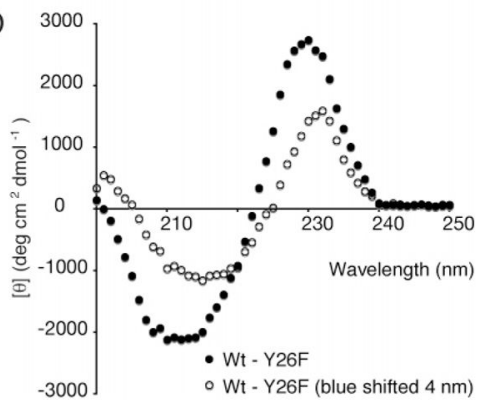

Figure 7.

Refolding and spectroscopic analysis of PagP exciton mutants. (A) Wild-type PagP and the Tyr26Phe, Trp66Phe, and Trp66His mutants were subjected to refolding in LDAO and evaluated by SDS-PAGE. (B and C) Wild-type PagP and the Tyr26Phe mutant were further analyzed by far-UV CD spectroscopy (B), and the thermal unfolding profiles were obtained by following the loss of the peak ellipticity bands (C). (D) Difference far-UV CD spectra determined by subtracting the Tyr26Phe PagP spectrum, with and without an introduced 4 nm blue shift, from the wild-type spectrum. 


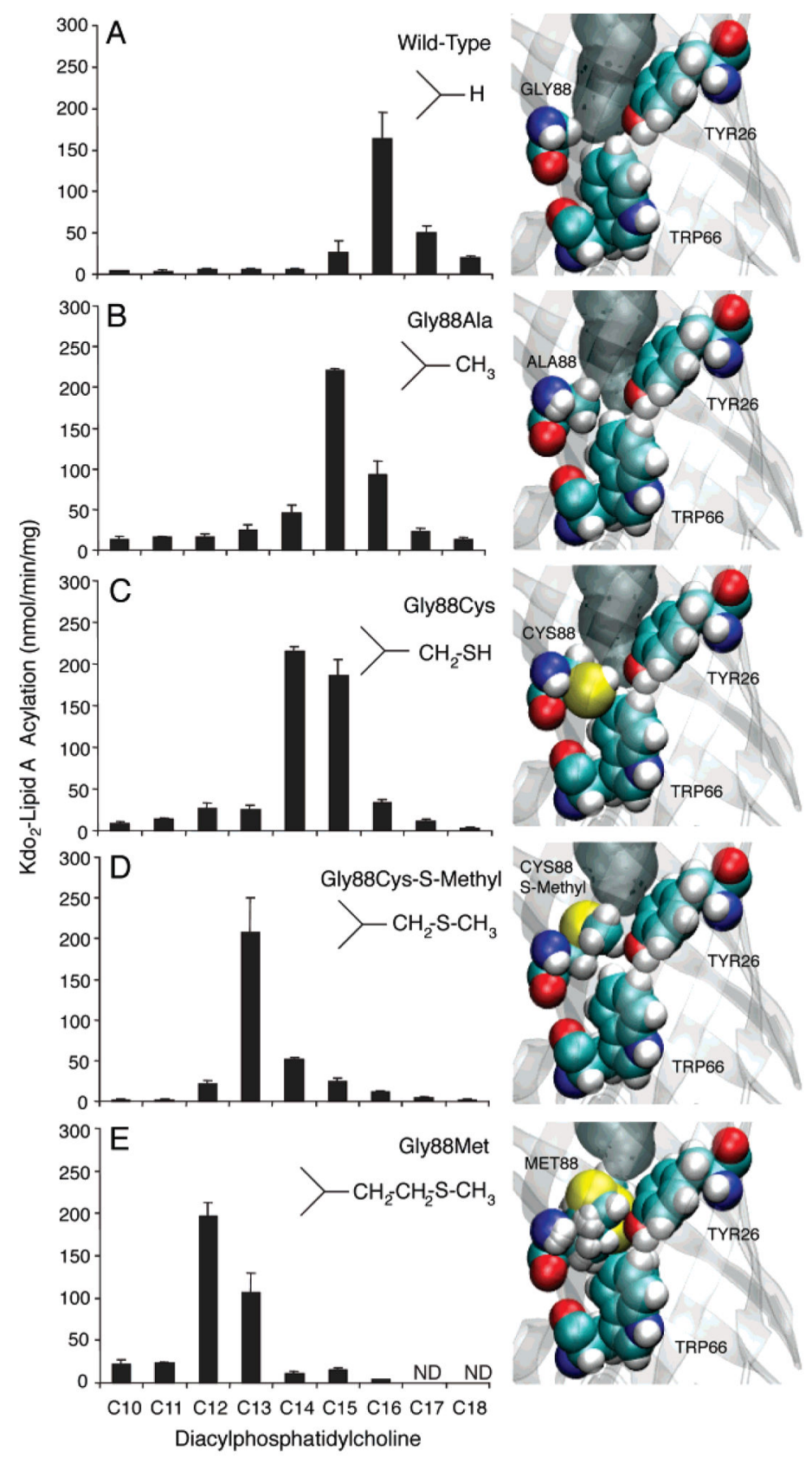

Figure 8.

Hydrocarbon ruler analysis of refolded PagP variants. Synthetic diacylphosphatidylcholines with saturated acyl chains varying in single methylene increments from 10 to 18 carbon atoms were used as donors for the enzymatic acylation of $\mathrm{Kdo}_{2}$-lipid A. Panels A-E present acyl-chain selection profiles for the refolded PagP variants. The structure of PagP (PDB entry 1THQ) emphasizing the positions of Gly 88 and the exciton interaction between Tyr26 and Trp66 is shown at the right of panel A. Contouring reveals the $\beta$-barrel interior region after removal of the LDAO detergent molecule. In silico mutagenesis followed by simulated 
annealing was performed to reveal a predicted orientation of the PagP Gly88 substitutions, which are shown at the right of panels B-E. ND means not detected. 


\section{Table 1}

Selective S-Methylation of Gly88Cys PagP Treated with MNBS

\begin{tabular}{llc}
\hline PagP protein $\boldsymbol{a}$ & theoretical mass (Da) & ESI-MS (Da) \\
\hline Gly88Cys control & 20221.58 & $20220.15 \pm 0.6$ \\
(Gly88Cys S-S dimer) & $(40441.14)$ & $(40439.32 \pm 1.0)$ \\
Gly88Cys with MNBS & 20235.61 & $20234.53 \pm 0.5$ \\
$\Delta$ with $S$-methyl & 14.03 & $14.38 \pm 1.1$ \\
wild-type control & 20175.49 & $20174.53 \pm 0.4$ \\
wild type with MNBS & 20175.49 & $20174.57 \pm 0.4$ \\
$\Delta$ with $S$-methyl & 0 & $-0.04 \pm 0.7$ \\
Gly88Ala & 20189.52 & $20190.63 \pm 1.7$ \\
Gly88Met & 20249.64 & $20249.41 \pm 0.7$ \\
Tyr26Phe & 20159.49 & $20161.80 \pm 2.3$ \\
Trp66Phe & 20136.45 & $20135.17 \pm 1.9$ \\
Trp66His & 20126.42 & $20128.01 \pm 2.2$ \\
\hline
\end{tabular}

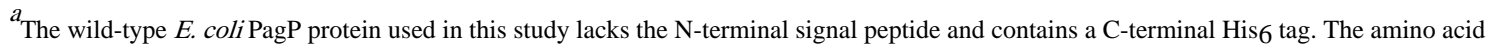
sequence with Gly88 underlined is as follows: MNADEWMT-TFRENIAQTWQQPEHYDLYIPAITWHARFAYDKEKTDRYNE RPWGGGFGLSRWDEKGNWHGLYAMAFKDSWNKWEPIAGYG-WESTWRPLADENFHLGLGFTAGVTARDNWNYIPLPVLLPLASVGYGPVTFQMTYIPGTYNNGNVYFAWMRFQFLEHHHHHH. 